\title{
The reduction of copper in porous matrices - The role of electrostatic stabilisation
}

\author{
O. P. Tkachenko ${ }^{\mathrm{a}}$, K. V. Klementiev ${ }^{\mathrm{b}}$, M. W. E. van den Berg, H. Gies ${ }^{\mathrm{c}}$, \\ W. Grünert
}

Lehrstuhl für Technische Chemie, Ruhr-Universität Bochum, Bochum, Germany (w.gruenert@techem.rub.de), ${ }^{\mathrm{a}}$ on leave from: N. D. Zelinsky Institute of Organic Chemistry, Russian Academy of Sciences, Moscow, Russia, ${ }^{b}$ Hasylab, Hamburg, Germany, ${ }^{c}$ Lehrstuhl für Kristallographie, Ruhr-Universität Bochum,

*Corresponding Author:

Prof. W. Grünert, Lehrstuhl für Technische Chemie, Ruhr-Universität Bochum, P. O. Box 102148, D-44780 Bochum, Germany, Tel. +49 234322 2088, Fax +49 234321 4115, email w.gruenert@techem.ruhr-uni-bochum.de

Running title: Reduction of $\mathrm{Cu}(\mathrm{II})$ in faujasite matrices

Keywords: $\mathrm{Cu}-\mathrm{Y}$; $\mathrm{Cu}$ in siliceous $\mathrm{Y}$; $\mathrm{Cu}$ reduction; electrostatic stabilisation; $\mathrm{Cu}$ reduction, influence of zinc on; TPR; XAFS 


\begin{abstract}
The redox properties of $\mathrm{Cu}(\mathrm{II})$ species in FAU matrices have been studied by temperature programmed reduction (TPR) in hydrogen and by XAFS analysis of the products obtained after (stationary) reduction treatments at various temperatures. The influence of the matrix polarity was investigated by comparing alumosilicate FAU (Y zeolite) with siliceous FAU. In addition, the influence of $\mathrm{Zn}$ ions on the reduction process was studied. It was found that both the matrix composition and the presence of zinc ions exert a significant influence on the course of the reduction. In $\mathrm{Y}$ zeolite, heat treatment which is known to transfer $\mathrm{Cu}(\mathrm{II})$ ions to remote sites $\left(\mathrm{S}_{\mathrm{I}}\right.$, $\mathrm{S}_{\mathrm{I}}, \mathrm{S}_{\mathrm{II}}$ ) affects the reduction process dramatically. $\mathrm{Cu}(\mathrm{II})$ is most easily reduced in siliceous FAU, but the reduction proceeds in two clearly separated steps. Between these steps, small $\mathrm{Cu}(0)$ nuclei coexist with $\mathrm{Cu}(\mathrm{I})$ species, apparently unable to activate hydrogen for the autocatalytic reduction of the remaining $\mathrm{Cu}$ ions. The polarity of the matrix causes an upshift of the $\mathrm{Cu}(\mathrm{II})$ reduction temperature (in TPR by $\approx 80 \mathrm{~K}$ for sites in the large cavity, by $\approx 105 \mathrm{~K}$ for the remote sites), but the reduction of $\mathrm{Cu}(\mathrm{I})$ depends strongly on the simultaneous presence of $\mathrm{Cu}(0)$ and on its ability to activate hydrogen and induce an autocatalytic reduction mechanism. While $\mathrm{Cu}(\mathrm{I})$ species in the large cavities are easily reduced to the metal, tending to segregate from the zeolite lattice, $\mathrm{Cu}(\mathrm{I})$ ions in remote sites are strongly stabilized towards further reduction and even traces of $\mathrm{Cu}$ metal form only at very high temperatures. In the presence of zinc ions, the $\mathrm{Cu}$ metal particles formed were found to be smaller than in zinc-free samples.
\end{abstract}




\section{Introduction}

The extensive attention for copper-modified zeolites as catalysts for environmental and other reactions of technical interest has induced a variety of investigations into the reduction behaviour of $\mathrm{Cu}(\mathrm{II})$ species in microporous alumosilicate matrices ${ }^{1-8}$. Temperature-programmed reduction (TPR) was the most frequently used tool in these studies ${ }^{1-4}$, but investigations by XAFS and photoemission techniques are known as well4,5,7,8. As opposed to bulk $\mathrm{CuO}, \mathrm{Cu}$ (II) in microporous alumosilicate matrices is reduced in two steps, which have been attributed to the reduction steps $\mathrm{Cu}(\mathrm{II}) \rightarrow \mathrm{Cu}(\mathrm{I})$ and $\mathrm{Cu}(\mathrm{I}) \rightarrow \mathrm{Cu}(0)$. The stabilisation of cations in the intrinsic electrostatic field of the zeolite matrix provides a convenient explanation for this observation. For the $\mathrm{Y}$ zeolite, it is known that the second reduction step proceeds only at very high temperatures $^{6}$, which may be attributed to a particular stabilisation exerted on the cations at the remote sites in the hexagonal prisms $\left(\mathrm{S}_{\mathrm{I}}\right)$ or in the sodalite cages $\left(\mathrm{S}_{\mathrm{I}^{\prime}}, \mathrm{S}_{\mathrm{II}}\right)$.

We have previously demonstrated that the two-step reduction scheme is not particular for alumosilicate zeolites but occurs in siliceous MFI (silicalite-1) as well ${ }^{9}$. Moreover, during the reduction of $\mathrm{Cu}(\mathrm{II})$ oxide clusters deposited into silicalite-1, $\mathrm{Cu}(0)$ nuclei were present already after the first reduction step without triggering an accelerated (autocatalytic) reduction of the remaining $\mathrm{Cu}(\mathrm{I})$ ions upon a temperature increase of almost $100 \mathrm{~K}$. Together with related observations in the course of $\mathrm{Cu}(\mathrm{II})$ reduction in $\mathrm{ZSM}-5$ and in MCM-48 (of different $\mathrm{Cu}$ content) this result gave rise to the conclusion that $\mathrm{Cu}$ metal nuclei are unable to activate hydrogen below a critical particle size.

During the work with the MFI matrices, a significant stabilisation of $\mathrm{Cu}$ ions that might be attributed to the intra-zeolite electrostatic potential was not observed. A more pronounced influence can be expected in zeolites with higher Al content, e.g. Y. With the FAU structure, the influence of the remote cation sites on the course of the reduction is an additional interesting feature. We report here studies on the reduction of $\mathrm{Cu}(\mathrm{II})$ in dealuminated as well as in alumosili- 
cate FAU. The influence of the remote sites has been traced by starting from $\mathrm{Cu}-\mathrm{Y}$ samples in calcined or in uncalcined initial state. Additionally, the influence of $\mathrm{Zn}$ ions on the reduction of $\mathrm{Cu}(\mathrm{II})$ ions has been investigated for siliceous and alumosilicate FAU. $\mathrm{Cu}$ - and $\mathrm{Zn}$-exchanged zeolites have been described as catalysts for the water gas shift reaction 10 . The present context is an effort to create model methanol synthesis catalysts by incorporating the $\mathrm{Cu} / \mathrm{ZnO}$ system into micro- or mesoporous matrices. More results of this project are published elsewhere ${ }^{11-14}$.

\section{Experimental}

Materials. Dealuminated Y (“DA-Y”) was a material produced by Degussa AG via the $\mathrm{SiCl}_{4}$ dealumination route, which avoids the creation of mesopores. The $\mathrm{Si} / \mathrm{Al}$ ratio is $120 . \mathrm{Na}-\mathrm{Y}$ ( $\mathrm{Si} / \mathrm{Al}$ $=2.3$ ) was kindly donated by Chemiewerk Bad Köstritz (Germany).

$\mathrm{Cu}-\mathrm{Y}$ was prepared under different conditions to obtain $\mathrm{Cu}$ ions predominantly in the large cavity or at remote sites. The first case was targeted by exchanging $\mathrm{Na}-\mathrm{Y}$ once with a $0.01 \mathrm{M}$ aqueous $\mathrm{Cu}$ acetate solution at room temperature for $24 \mathrm{~h}$ and drying the washed product at $333 \mathrm{~K}$ for 6 days ("CuNa-Y(D)"). A somewhat higher $\mathrm{Cu}$ loading was intended for the calcined $\mathrm{Cu}-\mathrm{Y}$ sample (“CuNa-Y(C))") by exchanging Na-Y twice with the same copper acetate solution at $373 \mathrm{~K}$ for $7 \mathrm{~h}$. After each exchange step, the washed zeolite was dried overnight and subjected to a thermal treatment in nitrogen to induce migration of $\mathrm{Cu}$ ions to the remote sites $(0.5 \mathrm{~K} / \mathrm{min}$ to $673 \mathrm{~K}$, with a $4 \mathrm{~h}$ isothermal period). Finally, $\mathrm{CuNa}-\mathrm{Y}(\mathrm{C})$ was calcined in synthetic air $\left(20 \% \mathrm{O}_{2}\right.$ in $\mathrm{N}_{2}$ ) at $673 \mathrm{~K}$.

The introduction of $\mathrm{Cu}$ into DA-Y was achieved with a procedure similar to that used for the silicalite matrix previously ${ }^{9}$, which is based on the mobility of $\mathrm{Cu}(\mathrm{I})$ species at high temperatures 15 . DA-Y was three times soaked in a $0.01 \mathrm{M}$ ethanolic copper acetate solution at $333 \mathrm{~K}$ for $22 \mathrm{~h}$. After each impregnation, the material was dried and heated in flowing $\mathrm{N}_{2}$ at $823 \mathrm{~K}$ for $4 \mathrm{~h}$ to induce the reduction of $\mathrm{Cu}(\mathrm{II})$ to $\mathrm{Cu}(\mathrm{I})$ and the diffusion of the latter into the pore system. Finally, the sample was calcined in synthetic air at $673 \mathrm{~K}$. 
Zinc was introduced into DA-Y by reacting it (after drying at $453 \mathrm{~K}$ in vacuum for $17 \mathrm{~h}$ ) with a 2 M solution of $\mathrm{Zn}\left(\mathrm{C}_{2} \mathrm{H}_{5}\right)_{2}$ in pentane, followed by calcination in synthetic air at $823 \mathrm{~K}^{12}$. Copper was additionally deposited into this sample by a procedure analogous to that used for the pure DA-Y (vide supra), however with impregnation in aqueous $\mathrm{Cu}$ acetate solution at $373 \mathrm{~K}$ and all thermal treatments performed at $823 \mathrm{~K}$. The $\mathrm{ZnCu}-\mathrm{Y}$ sample was prepared in a two-step sequence as well, with $\mathrm{Zn}$ introduced first by threefold ion exchange with a $1.6 \mathrm{M}$ aqueous zinc acetate solution at $373 \mathrm{~K}$ for $7 \mathrm{~h}$, followed by drying and thermal treatment in nitrogen at $673 \mathrm{~K}$ ( $4 \mathrm{~h}$, temperature ramp $0.5 \mathrm{~K} / \mathrm{min}$ ). The copper was then added by analogous threefold ion exchange with the $0.01 \mathrm{M}$ aqueous $\mathrm{Cu}$ acetate solution under reflux, with analogous intermediate thermal treatments in $\mathrm{N}_{2}$ at $673 \mathrm{~K}$ and final calcination in synthetic air at $673 \mathrm{~K}$.

The $\mathrm{Cu}$ and $\mathrm{Zn}$ contents of the samples as obtained by ICP-OES and confirmed by assessments via the step heights $(\mathrm{Cu} K$ and $\mathrm{Zn} K)$ in the XAFS spectra are summarized in Table 1.

Methods. The distribution of $\mathrm{Cu}$ and $\mathrm{Zn}$ species in the initial materials was investigated by a combination of XPS and X-ray-induced Auger electron spectroscopy (XAES). The spectra were measured with a Leybold LH 10 spectrometer equipped with an EA 10/100 multi-channel detector (Specs), using $\mathrm{MgK} \alpha$ irradiation $(10 \mathrm{kV}, 20 \mathrm{~mA})$. Spectra were referenced to the $\operatorname{Si}(2 \mathrm{p})$ line as an internal reference, which was set to $103.3 \mathrm{eV}$ for the siliceous DA-Y and to $102.6 \mathrm{eV}$ for the $\mathrm{Y}$ zeolite ${ }^{16}$. In the combination of XPS and XAES, an intra-zeolite location of $\mathrm{Cu}$ ions can be identified by an Auger parameter $\alpha_{\mathrm{Cu}}$ (sum of Cu LVV kinetic Auger energy and $\mathrm{Cu} 2 \mathrm{p}$ XPS binding energy) significantly below those of the bulk $\mathrm{Cu}$ oxides $7,17,18$. Unfortunately, this method is not applicable to the zinc component, which has to be, therefore, assessed on the basis of elemental ratios in the XPS sampling region alone. These ratios were derived from line intensity ratios using Scofield interaction cross sections 19 together with an empirical function describing the energy dependence of the analyser transmittance of the instrument used. 
TPR was performed with a mixture containing 4.2 vol- $\% \mathrm{H}_{2}$ in $\mathrm{He}(84 \mathrm{ml} / \mathrm{min})$, ramping the temperature at $10 \mathrm{~K} / \mathrm{min}$ from room temperature to $1070 \mathrm{~K}$. The $\mathrm{H}_{2}$ content of the effluent was measured by a catharometry-based instrument (Hydros, Fisher-Rosemount). For technical reasons, the TPR profiles of the $\mathrm{Zn}$-containing samples had to be measured in a slightly different setup that permitted maximum temperatures of $773 \mathrm{~K}$ only. The compatibility of the results in the two setups has been demonstrated in a previous paper ${ }^{9}$.

$\mathrm{Cu} K$ and $\mathrm{Zn} K$ XAFS spectra (edges at 8.979 and $9.659 \mathrm{keV}$ ) were measured in transmission mode at Hasylab E4 station (Hamburg) using a Si(111) double crystal monochromator (detuned to give $50 \%$ of maximum intensity for higher harmonics suppression). The experiments were performed with an in-situ cell described earlier ${ }^{20}$. In a typical experiment, a sample was heated in flowing diluted hydrogen $(5 \%$ in $\mathrm{He})$ to the first reduction temperature at $5 \mathrm{~K} / \mathrm{min}$ and kept there for 15 minutes (stationary reduction regime). After cooling to liquid nitrogen temperature, the spectrum of the absorption coefficient $\mu$ was taken twice (recording simultaneously the spectrum of a $\mathrm{Cu}(\mathrm{Zn})$ foil between the second and a third ionisation chamber for energy calibration). Subsequently, the sample was heated to the previous reduction temperature at $10 \mathrm{~K} / \mathrm{min}$, and the next temperature was established with $5 \mathrm{~K} / \mathrm{min}$.

Data treatment was carried out using the software package VIPER 21 . A Victoreen polynomial was fitted to the pre-edge region for background subtraction. The smooth atomic background $\mu_{0}$ was estimated using a smoothing cubic spline. The Fourier analysis of the $\mathrm{k}^{2}$-weighted experimental function $\chi=(\mu$ $\left.\mu_{0}\right) / \mu_{0}$ was performed with a Kaiser window. For the determination of structural parameters, theoretical references calculated by the FEFF $8.10 \operatorname{code}^{22}$ were used. To minimize the number of free parameters, equal backscatters were fitted with the same $\mathrm{E}_{0}$-shift wherever possible. The influence of the Cu EXAFS on the nearby $\mathrm{Zn}$ spectrum was tested with a representative sample with similar $\mathrm{Cu}$ and $\mathrm{Zn}$ contents, the $\mathrm{Cu}$ having been reduced to the metal state (the particular sample was supported on mesoporous MCM$48^{14}$ ). For this test, the model parameters for the $\mathrm{Cu}$ nanoparticles were extracted from the $\mathrm{CuK}$ spectrum, which was then simulated in full length (i.e. extending over the $\mathrm{Zn} K$ edge) with these data and 
subtracted from the $\mathrm{Zn} K$ XAFS. The comparison between uncorrected and corrected $\mathrm{Zn}$ EXAFS showed that the influence of the copper on the zinc spectrum is negligible under these conditions, which are similar to those encountered in the present study.

\section{Results}

XPS / XAES of initial samples. The surface-analytical investigation of the initial samples is summarized in Fig. 1 and Table 1. The figure shows the kinetic energy region where CuLVV Auger lines are expected, but also the $\mathrm{Na}_{\mathrm{KL}} \mathrm{L}_{1}$ and various $\mathrm{Zn}$ Auger lines. In all spectra, the $\mathrm{Cu}$ Auger line appears at a much lower kinetic energy (K.E.) than expected for $\mathrm{CuO}$ or $\mathrm{Cu}_{2} \mathrm{O}$, which is reflected in very low Auger parameters (Table 1). This shift suggests an intraporous location of the $\mathrm{Cu}$ species $7,8,17,18$, extra-zeolite oxide aggregates have not been formed to a significant extent in any of the samples including $\mathrm{ZnCu}-\mathrm{Y}$ where $\mathrm{Cu}$ is enriched in the external surface region. With the remaining samples, the comparison between surface and bulk $\mathrm{Cu} / \mathrm{Si}$ ratios confirms that copper is well distributed over the pore systems (Table 1). In CuNa-Y(C), the surface region was even significantly depleted in $\mathrm{Cu}$ - unlike the uncalcined sample. Unfortunately, the $\mathrm{Zn}$ Auger lines are not sensitive to extreme disorder or quasi-atomic dispersion of the $\mathrm{Zn}$ species. However, a largely homogeneous distribution of the zinc over the pore systems may be concluded from the absence of dramatic surface enrichment effects as well (Table 1). Assuming a stoichiometry of $\mathrm{Me} / \mathrm{Al}=0.5, \mathrm{ZnCu}-\mathrm{Y}$ is fully exchanged with $\mathrm{Zn} / \mathrm{Cu}$ ions. Its strong surface enrichment in $\mathrm{Cu}$ (and still notable enrichment in $\mathrm{Zn}$ ) indicates therefore that the surface region is significantly over-exchanged. While the formation of bulk $\mathrm{CuO}$ aggregates is excluded by the Auger spectra (vide supra), the presence of bulk $\mathrm{ZnO}$ aggregates cannot be excluded from the surface-analytical data. The EXAFS spectrum of the initial sample (Fig. 6a) proves, however, the absence of well-ordered zinc oxide structures.

Temperature-programmed reduction. In Figure 2, the TPR profiles $\left(\mathrm{H}_{2}\right.$ consumption related to $\mathrm{Cu}$ content) of $\mathrm{Cu}(\mathrm{II})$ in $\mathrm{FAU}$ matrices are compared with that of bulk $\mathrm{CuO}$, which is reduced in one very narrow peak below $470 \mathrm{~K}$. In the zinc-free samples, the zeolite-supported $\mathrm{Cu}(\mathrm{II}) \mathrm{spe}$ - 
cies are all reduced in two steps, but there are significant differences between the materials studied. In the siliceous DA-Y, the reduction starts at the lowest temperature. With the Y matrix, the onset is by $60-80 \mathrm{~K}$ higher (peak temperatures differing by 80 and $105 \mathrm{~K}$, respectively). As expected, the profiles for the dried and the calcined CuNa-Y differ strongly. It should be, noted, however, that the first reduction step occurs at almost the same temperature in both cases while the second step is strongly retarded in $\mathrm{CuNa}-\mathrm{Y}(\mathrm{C})$. In $\mathrm{CuNa}-\mathrm{Y}(\mathrm{D})$, the two reduction steps are almost merged into one while they are well separated with $\mathrm{Cu}-\mathrm{DAY}$ and $\mathrm{CuNa}-\mathrm{Y}(\mathrm{C})$. The presence of zinc changes the reduction kinetics strongly. In the DA-Y matrix, the reduction of copper starts at higher temperature than in absence of $\mathrm{Zn}$. Only one reduction peak is observed, the second one has been transformed into a pronounced tailing. In $\mathrm{ZnCu}-\mathrm{Y}$, the first reduction signal is much steeper, and a second peak emerges weakly on the tailing.

$X$-ray absorption. Figures 3 and 4 present examples of $\mathrm{Cu} K$ XAFS spectra measured after the reduction of $\mathrm{Cu}(\mathrm{II})$ in FAU matrices at different reduction temperatures $(\mathrm{a}$ - XANES, b - modulus of Fourier-transformed $\mathrm{k}^{2}$-weighted EXAFS function). The spectra of all initial samples and of the final reduction products are collected in Figure 5. The term "initial" refers to samples that had been heated in flowing He to $390 \mathrm{~K}$ at $5 \mathrm{~K} / \mathrm{min}$ and dried at this temperature for $15 \mathrm{~min}$.

From the initial EXAFS spectrum in Fig. 3b, it can be concluded the $\mathrm{Cu}$ oxide clusters present in DA-Y are very small although the comparison with other initial spectra (Fig. 5a) implies that the aggregation degree of copper is largest just in this sample. In Fig. 3a it can be seen that during reduction the pre-edge feature indicative of $\mathrm{Cu}(\mathrm{I})$ (see arrow) emerges already at $445 \mathrm{~K}$ and is very pronounced over a wide temperature range. In EXAFS, the second scattering signal $(\mathrm{Cu}-\mathrm{Cu}$ at a distance as in $\mathrm{CuO}$ ) fades away at low temperatures (Fig. 3b). However, already at $515 \mathrm{~K}$, a weak but significant scattering feature at the first distance of $\mathrm{Cu}$ metal appears. It grows moderately but remains small upon further temperature increase by $\approx 50 \mathrm{~K}$. As this is just the temperature region where XANES indicates the predominance of $\mathrm{Cu}(\mathrm{I})$, we have to conclude that $\mathrm{Cu}$ ions and $\mathrm{Cu}$ metal nuclei coexist in an extended temperature range. Above $590 \mathrm{~K}$, the $\mathrm{Cu}(0)-\mathrm{Cu}$ 
coordination in EXAFS grows significantly and the shape of the XANES approaches that of $\mathrm{Cu}$ metal. However, even at the highest reduction temperature $(650 \mathrm{~K})$, the $\mathrm{Cu}(0)-\mathrm{Cu}$ coordination remains much smaller than in the $\mathrm{Cu}$ foil, which is given in Fig. $3 \mathrm{~b}$ for comparison. The higher scattering events are weak and not well separated, and the XANES features typical of Cu metal remain washed out (Fig. 3a). These observations are very similar to those made with $\mathrm{Cu}(\mathrm{II})$ in silicalite- ${ }^{9}$, where, however, the temperature range of coexistence between $\mathrm{Cu}(\mathrm{I})$ and $\mathrm{Cu}(0) \mathrm{nu}-$ clei was even more extended.

With CuNa-Y(C), the course of the reduction is entirely different (Fig. 4). There are hardly any changes in the XANES up to $480 \mathrm{~K}$ where $\mathrm{Cu}$-DAY is already reduced to an appreciable extent (compare to Fig. 3a). At higher temperatures, the edge shifts to lower energy and gradually adopts a complicated shape characterized by three inflection points (Fig, 4a, spectra between 595 and $810 \mathrm{~K}$ ). In EXAFS (Fig. 4b), no feature that would indicate the presence of $\mathrm{Cu}(0)$ appears below $750 \mathrm{~K}$. The first coordination sphere $(\mathrm{O})$ decreases with increasing reduction temperature. The second sphere, which is usually assigned to $\mathrm{Cu}$ neighbours in $\mathrm{Cu}$ oxide clusters, is extremely small in the initial sample (see also Fig. 5a), but increases strongly upon reduction and remains intense up to high temperatures. Above $810 \mathrm{~K}$, a $\mathrm{Cu}(0)$ - $\mathrm{Cu}$ coordination emerges. At $865 \mathrm{~K}$, it is still much weaker than in the other samples (Fig. 5b), but scattering signals from the higher $\mathrm{Cu}$ metal coordinations are already visible. The considerable width of the scattering feature peaking at $2.15 \AA$ shows that there are still significant contributions both of the first and the second coordination sphere typical of $\mathrm{Cu}$ ions in this sample. Accordingly, the XANES is still more characteristic of the ionic state (though washed out) than of $\mathrm{Cu}$ metal (Fig. 4a).

The spectra measured during the reduction of the remaining samples may be well described by reference to those depicted in Figs. 3-5. The series taken with $\mathrm{CuNa}-\mathrm{Y}(\mathrm{D})$ has been earlier shown in ${ }^{13}$. In the initial CuNa-Y(D) (Fig. 5a) EXAFS indicates very low order beyond the first $(\mathrm{Cu}-\mathrm{O})$ shell. In the reduction series, the spectra obtained at low temperatures resemble those of $\mathrm{CuNa}-\mathrm{Y}(\mathrm{C})$ (cf. Fig. 4): the scattering intensity around $2.5 \AA$ (uncorrected) increases markedly 
when the temperature is raised to $495 \mathrm{~K}$ whereas the edge position (XANES) remains constant up to $485 \mathrm{~K}$ and indicates beginning reduction only at $495 \mathrm{~K}$. Already at $510 \mathrm{~K}$, however, a contribution of $\mathrm{Cu}(0)(\approx 2.15 \AA$, uncorrected $)$ emerges and grows strongly upon moderate temperature increase. In Fig. 5b, where the $\mathrm{Cu} K$ EXAFS spectra of the final reduction products are compared, it can be seen that unlike $\mathrm{Cu}$ metal produced in the DA-Y matrix, the metal aggregates formed in the uncalcined $\mathrm{Y}$ zeolite exhibit intense and well separated scattering features between 3 and $8 \AA$ (uncorrected) already after reduction at $570 \mathrm{~K}$. A slight asymmetry of the first $\mathrm{Cu}(0)$ $\mathrm{Cu}$ scattering feature to lower distances may indicate the presence of residual $\mathrm{Cu}$ ions.

In the zinc containing materials, the copper dispersion in the initial state is similar as in the samples without zinc (Fig. 5a): From the intensity of the second shell at ca. $2.5 \AA$ (uncorrected) one can judge that the cluster size is somewhat smaller in $\mathrm{ZnCu}-\mathrm{DAY}$ than in $\mathrm{Cu}-\mathrm{DAY}$ whereas there is no significant difference between the materials made with Y zeolite. The $\mathrm{Zn} K$ spectra (Fig. 6) imply that the short-range order around zinc is far from that in $\mathrm{ZnO}$. In the initial $\mathrm{ZnCu}-\mathrm{Y}$, no long-range order beyond the first $(\mathrm{O})$ neighbour can be seen at all. There is a weak higher shell in $\mathrm{ZnCu}-\mathrm{DAY}$, but as opposed to the $\mathrm{Cu}$ species (Fig. 5a), the higher shell in $\mathrm{ZnCu}-\mathrm{DAY}$ appears at a distance significantly different from that in the bulk oxide $(2.72 \AA$ vs. $2.86 \AA$ (uncorrected) in $\mathrm{ZnO}$ ), i.e., there are no oxide clusters with $\mathrm{ZnO}$ short-range order.

The reduction of $\mathrm{ZnCu}-\mathrm{DAY}$ will be described by reference to that of $\mathrm{Cu}-\mathrm{DAY}$ (Fig. 3). In the zinc-containing sample, hardly any changes appear up to $485 \mathrm{~K}$ where $\mathrm{Cu}(\mathrm{I})$ is already clearly observed in Cu-DAY (cf. Fig. 3a). In ZnCu-DAY, the XANES signature of $\mathrm{Cu}(\mathrm{I})$ emerges at 515 $\mathrm{K}$ but is never as pronounced as in absence of zinc. The $\mathrm{Cu}(0)-\mathrm{Cu}$ shell can be seen at $535 \mathrm{~K}$, but only at $650 \mathrm{~K}$, the reduction appears to be complete (see spectrum in Fig. 5b). In this higher temperature region, the course of reduction largely parallels that observed with $\mathrm{Cu}-\mathrm{DAY}$.

The reduction of $\mathrm{ZnCu}-\mathrm{Y}$ resembles that of $\mathrm{CuNa}-\mathrm{Y}(\mathrm{D})$ rather than of $\mathrm{CuNa}-\mathrm{Y}(\mathrm{C})$ although the zinc-containing sample had been calcined. After only minor changes up to $485 \mathrm{~K}$, an edge shift indicates the beginning $\mathrm{Cu}(\mathrm{I})$ formation at $525 \mathrm{~K}$. At $535 \mathrm{~K}$, the $\mathrm{Cu}(0)-\mathrm{Cu}$ path at $2.15 \AA$ (uncor- 
rected) appears very weakly, but already at $565 \mathrm{~K}$, the metal signal is fully developed though with a shoulder indicating residual $\mathrm{Cu}$ ions. This shoulder disappears gradually at higher reduction temperatures while the main $\mathrm{Cu}(0)-\mathrm{Cu}$ coordination grows only marginally to result in the spectrum for $650 \mathrm{~K}$ shown in Fig. $5 \mathrm{~b}$. In this spectrum, the signals of the higher shells are not separated at all. It should be noted, however, that with zinc-containing samples, the k range on which the Fourier transformation was based is shorter than with the $\mathrm{Zn}$-free catalysts due to the neighbouring $\mathrm{Zn} K$ edge. To allow a comparison, the spectrum of $\mathrm{CuNa}-\mathrm{Y}(\mathrm{D})$ obtained from the same $\mathrm{k}$ window is added on top, which confirms the observation of less separation between shells in the zinc-containing samples as compared to $\mathrm{CuNa}-\mathrm{Y}(\mathrm{D})$.

The composition of mixtures (in our case $-\mathrm{Cu}(\mathrm{II}), \mathrm{Cu}(\mathrm{I})$, and $\mathrm{Cu}(0)$ ) is usually determined by analyzing the contributions of the components to the XANES region. This approach is appropriate only if the XANES of the components are invariable throughout the series of mixtures. Unfortunately, this does not apply to our case because with highly disperse metal particles, the XANES depends on the degree of dispersion ${ }^{23}$, which is also illustrated by our own data (compare $\mathrm{Cu}$ obtained by reduction of $\mathrm{Cu}-\mathrm{DAY}$ and in the foil, Fig. 3a). Analogously, the XANES of our initial $\mathrm{Cu}(\mathrm{II})$ species differs from that of $\mathrm{CuO}$ and shows subtle differences between samples. Therefore the invariability of the component contribution is under doubt for all components. Indeed, in attempts to assess $\mathrm{Cu}(\mathrm{II}), \mathrm{Cu}(\mathrm{I})$ and $\mathrm{Cu}(0)$ percentages in reduced $\mathrm{Cu}-\mathrm{DAY}$ on this basis, the $\mathrm{Cu}(0)$ contributions at intermediate temperatures, which are clearly proven in the EXAFS (Fig. 3b), could not be extracted from the XANES. As introduced previously 9 , we have therefore extracted indirect information about the species distribution by decomposing the first shell in EXAFS into three contributions indicative of $\mathrm{Cu}(\mathrm{II}), \mathrm{Cu}(\mathrm{I})$, and $\mathrm{Cu}(0)(\mathrm{Cu}-\mathrm{O}$ for $\mathrm{Cu}(\mathrm{II})$ restricted to $1.94 \AA<\mathrm{r}<1.97 \AA, \mathrm{Cu}-\mathrm{O}$ for $\mathrm{Cu}(\mathrm{I})$ restricted to $1.84 \AA<\mathrm{r}<1.87 \AA, \mathrm{Cu}(0)$ - $\mathrm{Cu}$ free). Where necessary, a fourth shell $(\mathrm{Cu}-\mathrm{Cu}$ at 2.87-2.91 $\AA$ ) was included to represent remaining oxide clusters. It should be noted that this analysis considers the $\mathrm{Cu}$ ions to be part of a $\mathrm{Cu}$ oxide structure and is likely to fail with alumosilicate FAU where the coordination geometry imposed 
by the zeolite lattice should determine the $\mathrm{Cu}-\mathrm{O}$ distances (cf. 24-27). It has been, however, successfully applied to the reduction of an overexchanged $\mathrm{Cu}-\mathrm{ZSM}-5(\mathrm{Cu} / \mathrm{Al} \approx 0.45)^{9}$ Notably, coordination numbers (C.N.) cannot directly reflect the concentration of a species in the mixture because the C.N. of a given phase are primarily related to degrees of aggregation. However, when the species compared are in high, comparable dispersion, the trends of the C.N. should qualitatively reflect the abundance of the species.

The coordination numbers obtained by such fits are reported in Figures 7 and 8 in the form of "normalised coordination numbers" obtained by dividing the observed C.N. by those known from the respective bulk phases $\left(\mathrm{CuO}-4, \mathrm{Cu}_{2} \mathrm{O}-2, \mathrm{Cu}\right.$ metal - 12). Fig. 7 shows the data for samples made with the dealuminated Y zeolite. In the zinc-free sample (Fig. 7a), the normalised $\mathrm{Cu}(\mathrm{II})-\mathrm{O}$ C.N. first decreases without reduction products being detectable. We ascribe this to dehydration phenomena in the samples that had been stored in air after calcinations (where applied) and only dried at $390 \mathrm{~K}$ for the study of the initial state. As deduced above there is a broad temperature range during reduction of $\mathrm{Cu}-\mathrm{DAY}$ where $\mathrm{Cu}(\mathrm{I})$ and $\mathrm{Cu}(0)$ coexist, with hardly any change of the $\mathrm{Cu}(\mathrm{I})$ normalised C.N. A rapid reduction of the residual $\mathrm{Cu}$ ions is not induced by the zerovalent copper (Fig. 7a). Fig. 7b shows that zinc strongly retards the onset of $\mathrm{Cu}(\mathrm{II}) \mathrm{re}-$ duction. In $\mathrm{ZnCu}-\mathrm{DAY}$, the temperature range of coexisting $\mathrm{Cu}(\mathrm{I})$ and $\mathrm{Cu}(0)$ is narrower than in Cu-DAY. Above $550 \mathrm{~K}$, the catalyst state becomes very similar in both samples. This is in perfect agreement with the TPR profiles (Fig. 2) where the reduction rate peaks at higher temperature with $\mathrm{ZnCu}$-DAY whereas the pronounced tailing of the signal tends to a coincidence with that of the second maximum in the zinc-free sample.

Plots of the normalised C.N. vs. temperature for the materials prepared from Y zeolite are given in Fig. 8. In these samples, indications for $\mathrm{Cu}-\mathrm{O}$ contributions at $\approx 1.86 \AA$ have been found only in exceptional cases $(\mathrm{ZnCu}-\mathrm{Y}$ reduced at $535 \mathrm{~K}, \mathrm{CuNa}-\mathrm{Y}(\mathrm{C})$ at temperatures above $750 \mathrm{~K}$ (Fig. $8 \mathrm{c}, \mathrm{b}$ ) although the obvious shifts in the XANES at 500 - $550 \mathrm{~K}$ (cf. Fig. 4a) prove the reduction of $\mathrm{Cu} / \mathrm{II})$ to $\mathrm{Cu}(\mathrm{I})$. Given the not unexpected failure of our approach to distinguish $\mathrm{Cu}$ ions in $\mathrm{Y}$, 
the coordination number of the next $\mathrm{O}$ atoms at $\approx 1.96 \AA$ was normalized to (C.N.) $)_{0}=4$ in Fig. 8 , and the predominance of $\mathrm{Cu}(\mathrm{II})$ or $\mathrm{Cu}(\mathrm{I})$ as derived from the edge position was indicated by shading the data points.

As seen in the TPR curves, the reduction of $\mathrm{Cu}(\mathrm{II})$ sets on at much higher temperatures in $\mathrm{Y}$ than in DA-Y (Figs 2, 7a, 8a): $\mathrm{Cu}(\mathrm{I})$ formation was seen at $445 \mathrm{~K}$ with the latter, but at $495 \mathrm{~K}$ in $\mathrm{CuNa}-\mathrm{Y}(\mathrm{D})$ and only at $540 \mathrm{~K}$ with $\mathrm{CuNa}-\mathrm{Y}(\mathrm{C})$. On the other hand, the onset of $\mathrm{Cu}(0)$ formation occurs in the same temperature region in Cu-DAY and in CuNa-Y(D). In the alumosilicate matrix, however, the $\mathrm{Cu}(0)-\mathrm{Cu}$ normalised C.N. grows more rapidly once the first nuclei have been formed (Fig. 8a). As indicated above, calcination of $\mathrm{CuNa}-\mathrm{Y}$ changes the reduction behaviour dramatically (Fig. 8b). The influence of zinc is different in the siliceous and the alumosilicate FAU: In DA-Y, it clearly retards the reduction of $\mathrm{Cu}(\mathrm{II})$ while in $\mathrm{Y}$ it has the effect that the calcined sample (i.e. $\mathrm{ZnCu}-\mathrm{Y}$ ) behaves like the uncalcined $\mathrm{CuNa}-\mathrm{Y}(\mathrm{D})$ (as opposed to $\mathrm{CuNa}-\mathrm{Y}(\mathrm{C})$ ). In $\mathrm{ZnCu}-\mathrm{Y}$ the particularly steep increase of the normalized $\mathrm{Cu}(0) \mathrm{C} . \mathrm{N}$. between 535 and $565 \mathrm{~K}$ apparently reflects the pronounced autocatalytic rate maximum in the TPR profile (Fig. 2).

Although the $\mathrm{ZnK}$ spectra (Fig. 6) exhibit much less changes during reduction than the $\mathrm{CuK}$ spectra, some interesting observations can be made. As mentioned above, all spectra differ strongly from that of $\mathrm{ZnO}$, which is expected for $\mathrm{ZnCu}-\mathrm{Y}$, but not a priori for $\mathrm{ZnCu}-\mathrm{DAY}$. There, the XANES is almost completely featureless and resembles that found in zinc-modified mesoporous siliceous M41S phases ${ }^{12}$. Upon reduction, a small shift of the second scattering event (2.7 $\AA$, uncorrected) to lower distances is seen in EXAFS, which is, however too small to allow reliable conclusions to be drawn from model calculations. A significant reduction of $\mathrm{Zn}$ (II) can be excluded because there are no changes in the XANES, and it is doubtful that the shift seen in EXAFS could arise from nearby $\mathrm{Cu}(0)$.

In $\mathrm{ZnCu}-\mathrm{Y}$, the second EXAFS coordination sphere, which is completely absent in the initial sample, develops upon reduction of the sample as previously seen in the $\mathrm{Cu} K$ EXAFS spectra of $\mathrm{CuNa}-\mathrm{Y}(\mathrm{C})$ (Fig. 4b). There is, however, no evidence of $\mathrm{Zn}(\mathrm{II})$ reduction neither in the EXAFS 
nor in the XANES. Notably, significant changes of the XANES shape occur in this sample: Upon reduction, the principal maximum becomes weaker, and a clear shoulder emerges at an energy where $\mathrm{ZnO}$ exhibits a maximum. Due to the complicated theory of the XANES region, it is, however, difficult to relate these changes to definite structural modifications.

\section{Discussion}

In the initial samples, the transition-metal ions are well distributed over the porous matrices. This can be concluded from surface analysis (surface and bulk Me/Si atomic ratios (Table 1), $\mathrm{Cu} \mathrm{Au}-$ ger spectra and the $\mathrm{Cu}$ Auger parameters (Fig. 1, Table 1)) as well as from EXAFS (Fig. 5a, 6b). In no case, bulk oxide phases can be observed. In the fully exchanged $\mathrm{ZnCu}-\mathrm{Y}$ (according to $\mathrm{Me}^{2+} / \mathrm{Al}=0.5$ ), the considerable surface enrichment of $\mathrm{Cu}$, but also of $\mathrm{Zn}$ (Table 1) indicates an overexchange near the external surface. However, since EXAFS does no suggest significant aggregate formation (Fig. 6b, 5a; the $\mathrm{Cu}$ spectrum is similar to that of $\mathrm{CuNa}-\mathrm{Y}(\mathrm{D})$, with $1.6 \mathrm{wt}-\%$ $\mathrm{Cu}$ ), we suggest that the excess ions are exchanged together with extra-lattice oxygen (i.e. as $\left.\mathrm{Me}(\mathrm{OH})^{+}\right)$. In the siliceous DA-Y matrix, the formation of very small $\mathrm{Cu}$ oxide clusters is obvious from the EXAFS spectra (Fig. 5a). In all initial samples, the $\mathrm{Cu}-\mathrm{O}$ distances (fitted without constraint) were $\approx 1.96 \AA$, and the C.N. were near 4 . The $\mathrm{Cu}-\mathrm{O}$ distances reported for $\mathrm{Cu}(\mathrm{II})-\mathrm{Y}$ in earlier studies range from 1.96 to $2.01 \AA 24-27$.

In the reduction study, the results from the (instationary) TPR technique and from the (stationary) reduction runs analysed by XAFS are on the whole well in agreement. The reduction starts at the lowest temperature with Cu-DAY (Figs. 3, 7) and extends to the highest temperature with $\mathrm{CuNa}-\mathrm{Y}(\mathrm{C})$ (Fig. 4). $\mathrm{Cu}(\mathrm{II})$ is reduced at higher temperatures in the polar FAU matrix than in the dealuminated one, and the reduction is also delayed by the presence of $\mathrm{Zn}$ in DA-Y.

The results obtained with siliceous FAU and (uncalcined) alumosilicate FAU are related to each other in a similar way as those described in ${ }^{9}$ for siliceous and alumosilicate MFI. XAFS shows that both $\mathrm{Cu}(\mathrm{I})$ and some $\mathrm{Cu}(0)$ are formed readily in the two siliceous matrices and coexist over 
a wide temperature range with only moderate increase of the $\mathrm{Cu}(0)-\mathrm{Cu}$ normalised C.N., until the reduction rate increases again at high temperature (see Fig. 7 for $\mathrm{Cu}-\mathrm{DAY}$ ). This reflects the two-step reduction process observed in TPR (Fig. 2), however, with metal nuclei present already in the rate minimum between the two TPR peaks. With $\mathrm{CuNa}-\mathrm{Y}(\mathrm{D})$, XAFS sees the majority of $\mathrm{Cu}$ ions converted to the metal in the same temperature range as in the non-polar DA-Y matrix whreas the reduction of the initial $\mathrm{Cu}(\mathrm{II})$ starts at significantly higher temperature in the alumosilicate FAU. Such higher temperature of $\mathrm{Cu}(\mathrm{II})$ reduction onset is apparently a consequence of the electrostatic stabilisation of the cations by the polar alumosilicate matrix, because it was not found with the high-silica ZSM-5 zeolite 9 . Given the obvious stabilisation of charged particles by the $\mathrm{Y}$ matrix, it is unexpected to see the formation of the uncharged $\mathrm{Cu}$ metal in the same temperature range in siliceous and alumosilicate FAU.

The case of the calcined $\mathrm{CuNa}-\mathrm{Y}(\mathrm{C})$ is particular. It is well known that multiply-charged cations tend to occupy remote sites of the FAU structure $\left(\mathrm{S}_{\mathrm{I}}, \mathrm{S}_{\mathrm{I}}, \mathrm{S}_{\mathrm{II}}\right)$ where they experience a favorable electrostatic stabilisation 28 . The observation that during reduction of $\mathrm{CuNa}-\mathrm{Y}(\mathrm{C})$ no trace of $\mathrm{Cu}(0)$ can be found up to $750 \mathrm{~K}$ strongly suggests that the site exchange of $\mathrm{Cu}(\mathrm{II})$ with $\mathrm{Na}$ ions to access the remote sites was completely achieved by the thermal treatments applied. However, the stabilisation was much stronger with respect to $\mathrm{Cu}(\mathrm{I})$ than with $\mathrm{Cu}(\mathrm{II})$ where the upshift of the reduction temperature (relative to $\mathrm{CuNa}-\mathrm{Y}(\mathrm{D})$ ) was just $25 \mathrm{~K}$ (seen by TPR) to $50 \mathrm{~K}$ (seen by XAFS). This difference may be related to several factors. The remote sites offer a more compact coordination environment, which stabilises $\mathrm{Cu}(\mathrm{II})$ as well as $\mathrm{Cu}(\mathrm{I})$. From $\mathrm{Cu} K$ and $\mathrm{Zn} K$ EXAFS (Fig. 4b, 6b) it may be concluded that the order in these structures increases as the temperature is increased (vide infra). In the case of $\mathrm{Cu}$, this applies to the monovalent ion that has already formed under these conditions and experiences, therefore, an extra stabilisation. A different contribution may arise from the lower chance of aggregation for a metal atom formed on a remote site: in the large cavity, the higher probability to stabilise by aggregation with other $\mathrm{Cu}$ metal atoms (instead of encountering reverse reaction with zeolite $\mathrm{OH}$ groups) may further favour the 
reduction pathway. Once metal aggregates above a critical size are formed, the reduction process may be accelerated by hydrogen activated on them ${ }^{9}$, which is, however, completely absent in CuNa-Y(C) below $750 \mathrm{~K}$.

As expected, the spectroscopic signature of $\mathrm{Cu}(\mathrm{I})$ in $\mathrm{Y}$ differs strongly from that of $\mathrm{Cu}(\mathrm{I})$ in overexchanged ZSM-5, where the XANES was close to that in $\mathrm{Cu}_{2} \mathrm{O}$ and the EXAFS fit rendered a coexistence of $\mathrm{Cu}-\mathrm{O}$ distances at $\approx 1.85$ and $\approx 1.96 \AA$ even without constraints 9 . In $\mathrm{Y}$ zeolite, the $\mathrm{Cu}-\mathrm{O}$ distance remains near $1.96 \AA$ in a temperature region where both TPR and XANES (edge shift) suggest that the reduction of $\mathrm{Cu}$ (II) has taken place (T > $540 \mathrm{~K}$, Fig. 2, 4). At the same time, a complicated XANES shape appears. In 29 , XANES shapes of $40 \mathrm{Cu}$ compounds are compiled, but none of them corresponds to the shape observed during the reduction of $\mathrm{CuNa}-\mathrm{Y}(\mathrm{C})$, in particular in the $700-800 \mathrm{~K}$ temperature range (Fig. 4a). XANES spectra of $\mathrm{Cu}(\mathrm{I})$ in $\mathrm{Y}$ have been shown earlier in 24-26,30. A well-separated pre-edge peak was found for $\mathrm{Cu}(\mathrm{I})-\mathrm{Y}$ of high exchange degree in 24,25 . Opposed to this, Yamashita et al. 26 reported a shape reminiscent of the spectra in Fig. $4 \mathrm{a}$ for $\mathrm{Cu}(\mathrm{II})-\mathrm{Y}$ evacuated at $973 \mathrm{~K}$ but assign the structure to a mixture of $\mathrm{Cu}(\mathrm{I})$ and $\mathrm{Cu}(\mathrm{II})$. In our samples, edge-shift and TPR data render the presence of $\mathrm{Cu}(\mathrm{II})$ at the temperature of beginning $\mathrm{Cu}(0)$ formation $(750-810 \mathrm{~K})$ highly unlikely. Hence, the structure is probably caused by $\mathrm{Cu}(\mathrm{I})$ ions in different coordination geometries. It is obvious from 29 that the edge position of $\mathrm{Cu}(\mathrm{I})$ compounds is quite insensitive to coordination sphere and even ligand identity. Hence, the two shoulders at 8983 and 8989 eV (arrows in Fig. 4a) must not be considered as separate edge steps caused by two sites present. The major edge features of the $\mathrm{Cu} K$ XANES arise from $1 \mathrm{~s}-4 \mathrm{p}$ transitions, the splitting between $4 \mathrm{p}_{\mathrm{z}}$ and $4 \mathrm{p}_{\mathrm{xy}}$ exerting a pronounced influence on the signal shape. Hence, the structure observed may arise from $\mathrm{Cu}$ sites with very different ligand symmetry and, hence, different splitting between $4 p_{z}$ and $4 p_{x y}$. It would be an interesting and challenging task to assign these sites by studying the development in 
the XANES in a series of $\mathrm{CuNa}-\mathrm{Y}$ with different $\mathrm{Cu}$ ion distributions over the sites, which would have to be analysed by an independent technique, e.g. XRD.

It should be noted that the influence of the matrix on the $\mathrm{Cu}(\mathrm{I})$ signature holds also for CuNa$\mathrm{Y}(\mathrm{D})$ and $\mathrm{ZnCu}-\mathrm{Y}$ where the sample history and the reduction behaviour suggest that almost all $\mathrm{Cu}$ ions occupy sites in the large cavity although some might have managed to escape to remote positions in $\mathrm{CuNa}-\mathrm{Y}(\mathrm{D})$ during the reduction runs. Opposed to this, reduction caused the $\mathrm{Cu}-\mathrm{O}$ signal in $\mathrm{Cu}-\mathrm{ZSM}-5$ to shift to distances that allow for a large contribution of a $\mathrm{Cu}(\mathrm{I})$ component fixed between 1.84 and $1.87 \AA^{9}$. This is different from some other reports where $\mathrm{Cu}(\mathrm{I})-\mathrm{O}$ distances equal to or even larger than $\mathrm{Cu}(\mathrm{II})-\mathrm{O}$ have been observed for $\mathrm{Cu}-\mathrm{ZSM}-5$ of different preparation (e.g. solid-state ion exchange with $\mathrm{CuCl})^{31,32}$. It has been found earlier that the aqueous exchange via copper acetate solution leads to surface enrichment and formation of oligomeric clusters in the MFI matrix 8 , and the material studied here exhibited a different reduction behaviour than reported in other sources (cf. ${ }^{9}$ and literature cited there). Apparently, when overexchange is targeted with aqueous solutions of $\mathrm{Cu}$ salts, the ZSM-5 behaves as a siliceous rather than as an alumosilicate matrix: The Al present introduces hydrophilic properties which helps to introduce copper species into the pore system in large amounts (over-exchange phenomena). However, even at moderate degrees of over-exchange, most $\mathrm{Cu}$ species behave like oxide nanoclusters during reduction.

A notable feature of the EXAFS spectra of $\mathrm{Cu}$ and $\mathrm{Zn}$ ions in $\mathrm{Y}$ zeolite is the significant growth of the second coordination sphere with increasing reduction temperature. This is most obvious with $\mathrm{CuNa}-\mathrm{Y}(\mathrm{C})$ (Fig. 4b), but can also be observed in the $\mathrm{Zn} K$ spectra of $\mathrm{ZnCu}-\mathrm{Y}$ (Fig. 6b) and even with $\mathrm{CuNa}-\mathrm{Y}(\mathrm{D})$ up to the temperature of $\mathrm{Cu}$ metal formation (not shown). A possible explanation is that these signals arise from (initially disordered) oxide clusters as has been discussed in an earlier study on solid-state ion exchange of $\mathrm{NH}_{4}-\mathrm{Y}$ with $\mathrm{NiCl}_{2}, \mathrm{CuCl}$, or $\mathrm{ZnCl}_{2} 30$. However, given the straightforward reduction both of extra-zeolite $\mathrm{CuO}$ and of $\mathrm{Cu}(\mathrm{II})$ in the 
large cavity of $\mathrm{Y}$ (cf. CuNa-Y(D)), we can safely exclude this situation for copper in $\mathrm{CuNa}$ $\mathrm{Y}(\mathrm{C})$, and we believe the zinc case to be similar. The trend to higher (or different) order upon heat treatment may also arise from cation migration, e.g. upon reduction of $\mathrm{Cu}(\mathrm{II})$ to $\mathrm{Cu}(\mathrm{I})$. However, in $\mathrm{CuNa}-\mathrm{Y}(\mathrm{C})$, the higher shells increase already at $\mathrm{T} \leq 480 \mathrm{~K}$ where reduction is negligible (Fig. 5b), and the same phenomenon occurs in the spectra of the irreducible Zn ions (Fig. 6b). We believe therefore that the growth of the second coordination sphere with increasing reduction temperature reflects that the transition-metal ions are not well ordered in the Y structure as long as they are not fully dehydrated.

It was attempted to analyse the average coordination sphere of the $\mathrm{Cu}$ ions in $\mathrm{CuNa}-\mathrm{Y}(\mathrm{C})$ from representative spectra (after reduction at 485 and $595 \mathrm{~K}$ ). Examples for the fits are given in Fig. 9, the model parameters are summarized in Table 2. Considering these data, it should be noted that in the analysis of the second shell (between 2.3 and $3.2 \AA$, uncorrected) it is possible to obtain good fits with a great number of models that do not bear chemical sense: When using different scatterers $(\mathrm{O}, \mathrm{Al}, \mathrm{Si}, \mathrm{Cu})$ many geometries may result in partially destructive interference to reproduce the relatively weak signal in the spectrum. However, any solution with realistic coordination numbers invariably involved also $\mathrm{Cu}$ neighbours, i.e., the presence of $\mathrm{Cu}$ in the second $\mathrm{Cu}$ coordination sphere is very likely. Indeed, in 26 , a similar spectrum was analyzed with a $\mathrm{Cu}-$ $\mathrm{Cu}$ shell, however at an unrealistic C.N. of 6. In single-shell fits, the first (O) coordination number tended to a value of 4 (Table 2).

The fits presented in Fig. 9 and Table 2 have been obtained with constraints derived from a model in which $\mathrm{S}_{\mathrm{I}}$ and $\mathrm{S}_{\mathrm{I}}$, sites are occupied. It has been argued that adjacent $\mathrm{S}_{\mathrm{I}}$ and $\mathrm{S}_{\mathrm{I}}$, sites are not likely to be occupied for electrostatic reasons 24 . However, such situation, in which the monovalent cations are shielded by the six-ring oxygens, could well explain the $\mathrm{Cu}-\mathrm{Cu}$ distances found in the fits (slightly above $3 \AA$, cf. Table 2) as well as the C.N. of 4 obtained for the nearest $\mathrm{O}$ shell ( 6 for $\mathrm{S}_{\mathrm{I}}, 3$ for the two $\mathrm{S}_{\mathrm{I}}$, sites). An alternative explanation for $\mathrm{Cu}-\mathrm{Cu}$ coordinations observed could be a coexistence (in each sodalite cage) of more than $2 \mathrm{Cu}$ ions in $\mathrm{I}^{*}$ sites (center of 
six-membered ring of hexagonal prism ${ }^{24}$ ). The constraint used for the fits presented here has been derived from the former model (average C.N. of 8 for the sum of T atoms (Al, Si) - 12 for $\mathrm{S}_{\mathrm{I}}, 6$ for the two $\mathrm{S}_{1}$, sites). With one $\mathrm{S}_{\mathrm{I}},-\mathrm{S}_{\mathrm{I}}-\mathrm{S}_{\mathrm{I}}$, string, the $\mathrm{Cu}-\mathrm{Cu}$ C.N. will tend to 1.33 (2 for $\mathrm{S}_{\mathrm{I}}$, 1 for the two $\mathrm{S}_{\mathrm{I}}$, sites), but larger C.N. might be explained by including more than one $\mathrm{S}_{\mathrm{I}}$, site per sodalite cage because the distance between two $\mathrm{S}_{\mathrm{I}}$, positions in the sodalite cage should be similar. The models neglect possibly present $\mathrm{Na}$ ions and asymmetric cation positions that might arise from asymmetric $\mathrm{Al}$ distributions in the six-rings. In the models of type $\mathrm{A}$, the $\mathrm{Cu}-\mathrm{Si}$ and $\mathrm{Cu}-\mathrm{Al}$ distances and Debye-Waller factors were kept identical and a C.N. of 2 was set for the $\mathrm{Cu}-\mathrm{Cu}$ scattering path. Releasing these constraints (models B) led to significant improvements, but for the sample reduced at $595 \mathrm{~K}$, the $\mathrm{Cu}-\mathrm{Cu} \mathrm{C} . \mathrm{N}$. tended towards the upper limit set (3.0). While the higher degree of ordering among $\mathrm{Cu}$ ions, which is indicated by this result, may reflect a real effect, the significance of the models obtained should not be overemphasized. Given the large number of parameters and ill-specified constraints, they may serve to illustrate that plausible situations may be reflected in the data, but not to prove any structure hypothesis.

A comparison of $\mathrm{Cu} K$ EXAFS spectra measured after reduction of $\mathrm{Cu}(\mathrm{II})$ in different matrices (Fig. 5b; CuNa-Y(C) omitted because complete reduction was not achieved) shows that different products have been formed. The spectrum of $\mathrm{CuNa}-\mathrm{Y}(\mathrm{D})$ differs from the remaining ones in a pronounced separation between the higher scattering features (3-5 $\AA$ (uncorrected)) and in a larger first $\mathrm{Cu}-\mathrm{Cu}$ distance (Fig. 5b), which is similar as in the spectrum of the $\mathrm{Cu}$ foil. The first Cu-Cu C.N. is, however, much smaller in the reduced Y sample (5.6 vs. 12). Based on a geometrical correlation derived in 33 , a C.N. of 5.6 corresponds to an average particle diameter of 8$9 \AA$ (spherical shape assumed), which is obviously at variance with the pronounced scattering from distances between 6 and $8 \AA$ (uncorrected) and the lack of amplitude decay between 3 and $5 \AA$ (uncorrected)). Therefore, though dominated by the contribution of very large particles, the spectrum indicates the simultaneous presence of a significant minority of very small entities 
(probably oligomers because they affect only the first shell). Their existence may be favoured by the relative low reduction temperature at which this series was finished $(570 \mathrm{~K})$.

With Cu-DAY and ZnCu-DAY (both reduced at $650 \mathrm{~K}$, Fig. 5b), the C.N. of the first $\mathrm{Cu}-\mathrm{Cu}$ shell (6.9 and 7.8, respectively, vs. 5.6) indicates a somewhat larger average particle size than in CuNa-Y(D) (10 $\AA$ and $11.5 \AA$, respectively, vs. $8.5 \AA$ ), but the intensity of the higher shells is smaller than in the latter. Remarkably, the higher shells are least intense with the reduced $\mathrm{ZnCu}-$ DAY where scattering beyond $6 \AA$ (uncorrected) is insignificant. This sample appears to have the most homogeneous particle size distribution, the average size of $11.5 \AA$ being well compatible with the size of the large cavity in FAU. Notably, the first $\mathrm{Cu}-\mathrm{Cu}$ distance found here is significantly below that extracted from the spectrum of the $\mathrm{Cu}$ foil (2.51 $\AA$ vs. $2.543 \AA)$. Such contraction is typical for small metal clusters (see also ref. ${ }^{9}$ ). For $\mathrm{Cu}-\mathrm{DAY}$, the stronger scattering intensity above $6 \AA$ (uncorrected) and the less pronounced amplitude decay between 3 and $5 \AA$ (uncorrected) suggest the presence of larger particles. The reduced $\mathrm{ZnCu}-\mathrm{Y}$ again combines a small average particle size (C.N. - 5.5, d - 8-9 Å) with significant scattering from high distances (Fig. 5b). Apparently, large particles coexist with smaller ones in this case as well.

The influence of zinc upon the reduction of $\mathrm{Cu}$ ions differs for the two matrices studied. In DA$\mathrm{Y}$, a stabilisation of $\mathrm{Cu}(\mathrm{II})$ by the zinc species present is quite obvious from Fig. 7. The particle size distribution of the $\mathrm{Cu}$ metal formed was more homogeneous in presence of zinc (Fig. 5b), with the formation of large particles avoided despite the significantly larger copper content of $\mathrm{ZnCu}-\mathrm{DAY}$. In $\mathrm{Y}$ zeolite, the $\mathrm{Zn}$ introduced first occupies the sodalite cages and is apparently not replaced to any significant extent by the copper loaded secondly, despite the final calcination process. Therefore, the reduction behaviour of $\mathrm{ZnCu}-\mathrm{Y}$ resembles that of the uncalcined $\mathrm{CuNa}$ Y(D) (Fig. 8). However, also in this case, there are strong indications that the presence of zinc retards the formation of large particles (without preventing it completely). This is quite surprising because the reduction, which exhibits the attributes of an autocatalytic step, is much more rapid with $\mathrm{ZnCu}-\mathrm{Y}$ than with $\mathrm{CuNa}-\mathrm{Y}$ (D) (Fig. 2), probably because of the higher copper content 
in the former. It is hard to conceive how irreducible ions in the remote sites should affect a reduction process in the large cavities. Thus, the effect seems to indicate that there are also $\mathrm{Zn}$ ions located in the large cavity in this highly exchanged sample, which contains $\mathrm{Zn}$ and $\mathrm{Cu}$ in an atomic ratio of $\approx 2: 1$. The mechanism that keeps the copper better dispersed in presence of zinc remains, however, unclear.

\section{Conclusions}

The reduction of $\mathrm{Cu}(\mathrm{II})$ species in FAU matrices depends on the composition of the matrices, on the sample history, and on the presence of additional constituents, e.g. zinc ions. In a siliceous FAU matrix, $\mathrm{Cu}(\mathrm{II})$ is reduced in two steps, with $\mathrm{Cu}(0)$ nuclei already present after the first step. These (oligomeric) nuclei seem to be unable to induce an autocatalytic reduction of the remaining $\mathrm{Cu}$ ions. In alumosilicate FAU (Y zeolite), the reduction depends strongly on the sample history, with strong retardation of metal formation caused by previous calcinations of the material (stabilisation in remote cation sites), but straightforward metal formation - accompanied by formation of large, probably extra-zeolite particles - without calcination (sites in the large cavity). The presence of zinc delays the reduction of $\mathrm{Cu}$ (II) in siliceous FAU and leads to the formation of smaller $\mathrm{Cu}$ particles both in siliceous and alumosilicate FAU.

In $\mathrm{Y}$ zeolite, the short-range order around $\mathrm{Cu}$ and $\mathrm{Zn}$ ions was found to increase upon heating or reducing the samples (by reference to drying at $393 \mathrm{~K}$ ). The most pronounced order was seen with $\mathrm{Cu}(\mathrm{I})$ ions in remote positions, which exhibited a unique XANES signature. Electrostatic stabilisation of $\mathrm{Cu}$ ions by the intra-zeolite electrostatic potentials is reflected in an upshift of the $\mathrm{Cu}$ (II) reduction temperature relative to the siliceous matrix. No stabilisation was found with ZSM-5 9 where the intermediate $\mathrm{Cu}(\mathrm{I})$ ions exhibited even the spectroscopic signature of $\mathrm{Cu}(\mathrm{I})$ in oxide clusters. In Y, the stabilisation led to a moderate upshift of the reduction temperature for positions in the large cavity ( $80 \mathrm{~K}$ in TPR), and an additional slight shift for the remote positions 
( $25 \mathrm{~K}$ in TPR). A strong stabilisation was seen only for $\mathrm{Cu}(\mathrm{I})$ in the remote sites were $\mathrm{Cu}(0)$ was not formed at all at low temperatures.

\section{Acknowledgements}

The work has been funded by the German Science Foundation (DFG) in the framework of the Collaborative Research Center "Metal-substrate Interactions in Heterogeneous Catalysis" (SFB 558), which is gratefully acknowledged. Thanks are due to Mrs. Susanne Wiedemeyer and Mr. Vijay Narkhede for the TPR measurements, and to Dr. I. Ritzkopf (Max-Planck-Institut für Kohlenforschung, Mülheim/Ruhr, Germany) for performing the reaction of DA-Y with diethyl zinc. 


\section{References}

1 R. Bulanek, B. Wichterlová, Z. Sobalik, and J. Tichy, Appl. Catal. B, 2001, 31, 13.

2 C. Torre-Abreu, C. Henriques, F. R. Ribeiro, G. Delahay, and M. F. Ribeiro, Catal. Today, 1999, 54, 407.

3 C. Torre-Abreu, M. E. Ribeiro, C. Henriques, and G. Delahay, Appl. Catal. B, 1997, 14, 261.

4 M. K. Neylon, C. L. Marshall, and A. J. Kropf, J. Am. Chem. Soc., 2002, 124, 5457.

5 A. Yamaguchi, T. Shido, Y. Inada, T. Kogure, K. Asakura, M. Nomura, and Y. Iwasawa, Catal. Lett., 2000, 68, 139.

6 G. Moretti and W. M. H. Sachtler, J. Catal., 1989, 115, 205.

7 E. S. Shpiro, W. Grünert, R. W. Joyner, and G. N. Baeva, Catal. Lett., 1994, 24, 159.

8 W. Grünert, N. W. Hayes, R. W. Joyner, E. S. Shpiro, M. R. H. Siddiqui, and G. N. Baeva, J. Phys. Chem., 1994, 98, 10832.

9 O. P. Tkachenko, K. V. Klementiev, M. W. E. van den Berg, N. Koc, M. Bandyopadhyay, A. Birkner, C. Wöll, H. Gies, and W. Grünert, J. Phys. Chem. B, 2005, 109, 20979.

10 T. R. Oliveira de Souza, S. M. de Oliveira Brito, and H. M. Carvalho Andrade, Appl. Catal. B, 1999, 178, 7.

11 H. Gies, S. Grabowski, M. Bandyopadhyay, W. Grünert, O. P. Tkachenko, K. V. Klementiev, and A. Birkner, Microporous Mesopor. Mater., 2003, 60, 31.

12 O. P. Tkachenko, K. V. Klementiev, E. Löffler, I. Ritzkopf, F. Schüth, M. Bandyopadhyay, S. Grabowski, H. Gies, V. Hagen, M. Muhler, L. Lu, R. A. Fischer, and W. Grünert, Phys. Chem. Chem. Phys., 2003, 5, 4325. 
13 O. P. Tkachenko, K. V. Klementiev, N. Koc, X. Yu, M. Bandyopadhyay, S. Grabowski, H. Gies, and W. Grünert, Stud. Surf. Sci. Catal. 2004, 154, 1670.

14 S. Polarz, F. Neues, M. W. E. van den Berg, W. Grünert, and L. Khodeir, J. Am. Chem. Soc., 2005, 127, 12028.

15 T. Liese and W. Grünert, J. Catal., 1997, 172, 34.

16 W. Grünert, M. Muhler, K.-P. Schroeder, J. Sauer, and R. Schlögl, J. Phys. Chem., 1994, 98, 10920.

17 B. A. Sexton, T. D. Smith, and J. V. Sanders, J. Electron Spectrosc. Relat. Phenom., 1985, 35, 27.

18 I. Jirka, B. Wichterlova, and M. Maryska, Stud. Surf. Sci. Catal., 1991, 69, 269.

19 J. H. Scofield, J. Electron Spectrosc. Relat. Phenom., 1976, 8, 129.

20 F. W. H. Kampers, T. M. J. Maas, J. van Grondelle, D. C. Brinkgreve, and D. C. Koningsberger, Rev. Sci. Instr., 1989, 60, 2635.

21 K. V. Klementiev, VIPER for Windows (Visual Processing in EXAFS Researches), freeware, www.desy.de/ klmn/viper.html.

22 A. L. Ankudinov, B. Ravel, J. J. Rehr, and S. D. Conradson, Phys. Rev. B, 1998, 58, 7565.

23 D. C. Bazin, D. A. Sayers, and J. J. Rehr, J. Phys. Chem. B, 1997, 101, 1140.

24 G. T. Palomino, S. Bordiga, A. Zecchina, G. L. Marra, C. Lamberti, J. Phys. Chem. B 2000, 104, 8641.

25 C. Lamberti, G. Spoto, D. Scarano, C. Paze, M. Salvalaggio, S. Bordiga, A. Zecchina, G. T. Palomino, F. Dacapito, Chem. Phys. Lett. 1997, 269, 500.

26 H. Yamashita, M. Matsuoka, K. Tsuji, Y. Shioya, M. Anpo, M. Che, J. Phys. Chem. 1996, 100, 397. 
27 S. Tanabe, H. Matsumoto, J. Phys. Chem. 1990, 94, 4207.

28 E. F. T. Lee and L. V. C. Rees, Zeolites, 1987, 7, 143.

29 L.-S. Kau, D. J. Spira-Solomon, J. E. Penner-Hahn, K. O. Hodgson, and E. I. Solomon, J. Am. Chem. Soc., 1987, 109, 6433.

30 H. Förster, and U. Hatje, Solid State Ionics, 1997, 101-103, 425.

31 C. Lamberti, S. Bordiga, M. Salvalaggio, G. Spoto, A. Zecchina, F. Geobaldo, G. Vlaic, M. Bellatreccia, J. Phys. Chem. B 1997, 101, 344.

32 R. Kumashiro, Y. Kuroda, M. Nagao, M. J. Phys. Chem. B 1999, 103, 89.

33 M. Borovski, J. Phys, IV, 1997, 7, C2. 
Table 1 - Samples used in the present study - composition (by ICP) and surface-analytical results

\begin{tabular}{|c|c|cc|cc|cc|c|}
\hline \multirow{2}{*}{ Code } & \multirow{2}{*}{ Matrix } & \multicolumn{2}{|c|}{ wt-\% metal } & \multicolumn{2}{|c|}{$\begin{array}{c}\text { Me/Si atomic } \\
\text { ratio }\end{array}$} & \multicolumn{2}{|c|}{$(\mathrm{Me} / \mathrm{Si})_{\mathrm{XPS}}$} & \multirow{2}{*}{$\alpha_{\mathrm{Cu}}, \mathrm{eV}$} \\
\cline { 3 - 8 } & & $\mathrm{Cu}$ & $\mathrm{Zn}$ & $\mathrm{Cu}$ & $\mathrm{Zn}$ & $\mathrm{Cu}$ & $\mathrm{Zn}$ & \\
\hline $\mathrm{Cu}-\mathrm{DAY}$ & $\mathrm{DA}-\mathrm{Y}$ & 1.1 & - & $0.010_{5}$ & - & 0.007 & - & 1846.9 \\
$\mathrm{CuNa}-\mathrm{Y}(\mathrm{D})$ & $\mathrm{Na}-\mathrm{Y}$ & $1.6^{\mathrm{a}}$ & - & 0.022 & - & 0.018 & - & 1846.9 \\
$\mathrm{CuNa}-\mathrm{Y}(\mathrm{C})$ & $\mathrm{Na}-\mathrm{Y}$ & $2.6^{\mathrm{a}}$ & - & 0.036 & - & 0.005 & - & 1846.4 \\
$\mathrm{ZnCu}-\mathrm{DAY}$ & $\mathrm{DA}-\mathrm{Y}$ & 3.5 & 6.3 & 0.037 & 0.064 & 0.032 & 0.054 & 1846.4 \\
$\mathrm{ZnCu}-\mathrm{Y}$ & $\mathrm{Na}-\mathrm{Y}$ & 4.9 & 10.0 & 0.078 & 0.155 & 0.25 & 0.33 & 1846.8 \\
\hline
\end{tabular}

${ }^{\mathrm{a}}$ exchange degrees $(\mathrm{Cu} / \mathrm{Al}=0.5)-11.5 \%$ for $\mathrm{CuNa}-\mathrm{Y}(\mathrm{D})$ and $18.5 \%$ for $\mathrm{CuNa}-\mathrm{Y}(\mathrm{C})$ 
Table 2 - Model parameters for the simulation of $\mathrm{CuK}$ EXAFS spectra measured after reduction of CuNa-Y(C) at $485 \mathrm{~K}$ and $595 \mathrm{~K}$ (Fig. 9)

\begin{tabular}{|c|c|c|c|c|}
\hline Neighbor & $\mathrm{r}, \AA$ & C.N. & $10^{3} \sigma^{2}, \AA^{-2}$ & $\mathrm{E}_{0}, \mathrm{eV}$ \\
\hline \multicolumn{5}{|c|}{ reduction at $485 \mathrm{~K}$} \\
\hline \multicolumn{5}{|l|}{ Model A } \\
\hline $\mathrm{O}$ & 1.947 & 4.8 & 8.1 & 10.8 \\
\hline $\mathrm{Al}$ & 2.76 & $2.4^{\mathrm{b}}$ & 24.5 & 17.8 \\
\hline $\mathrm{Si}$ & $2.76^{\mathrm{a}}$ & $5.6^{\mathrm{b}}$ & $24.5^{\mathrm{a}}$ & 10.8 \\
\hline $\mathrm{Cu}$ & 3.40 & $2.0^{\mathrm{c}}$ & 11.6 & 3.8 \\
\hline \multicolumn{5}{|l|}{ Model B } \\
\hline $\mathrm{O}$ & 1.949 & 4.1 & 6.4 & 11.9 \\
\hline $\mathrm{Al}$ & 2.54 & $2.4^{\mathrm{b}}$ & 7.9 & 20.9 \\
\hline $\mathrm{Si}$ & 2.70 & $5.6^{\mathrm{b}}$ & 10.6 & 12.0 \\
\hline $\mathrm{Cu}$ & 3.10 & 1.3 & 9.5 & 19.2 \\
\hline \multicolumn{5}{|c|}{ reduction at $595 \mathrm{~K}$} \\
\hline \multicolumn{5}{|l|}{ Model A } \\
\hline $\mathrm{O}$ & 1.972 & 2.7 & 6.8 & 11.8 \\
\hline $\mathrm{Al}$ & 3.12 & $2.4^{\mathrm{b}}$ & 17.1 & 4.8 \\
\hline $\mathrm{Si}$ & $3.12^{\mathrm{a}}$ & $5.6^{\mathrm{b}}$ & $17.1^{\mathrm{a}}$ & -2.2 \\
\hline $\mathrm{Cu}$ & 3.36 & $2.0 \mathrm{c}$ & 19.3 & 4.8 \\
\hline \multicolumn{5}{|l|}{ Model B } \\
\hline $\mathrm{O}$ & 1.996 & $4.1_{5}$ & 11.5 & 12.1 \\
\hline $\mathrm{Al}$ & 2.47 & $2.4^{\mathrm{b}}$ & 2.6 & 9.2 \\
\hline $\mathrm{Si}$ & 2.56 & $5.6^{\mathrm{b}}$ & 7.4 & -5.1 \\
\hline $\mathrm{Cu}$ & 2.99 & $3.0^{\mathrm{c}}$ & 15.7 & 16.0 \\
\hline
\end{tabular}

${ }^{a}$ fixed to corresponding value of $\mathrm{Cu}-\mathrm{Al}$ coordination both coordinations ( 8 : see text)

${ }^{\mathrm{c}}$ fixed
${ }^{b}$ fixed by $\mathrm{Si} / \mathrm{Al}$ ratio and fixed sum of dupper limit 


\section{Legends}

Figure 1 - X-ray induced Auger spectra of $\mathrm{Cu}$ species in FAU matrices (samples described in Table 1).

Figure 2 - TPR profiles of $\mathrm{Cu}$ oxide species in FAU matrices, compared with $\mathrm{CuO}$.

Figure 3 - $\mathrm{CuK}$ XAFS spectra measured after reduction of $\mathrm{Cu}-\mathrm{DAY}$ at different temperatures indicated in the figure, comparison with $\mathrm{Cu}$ foil. a - XANES, $\mathrm{b}$ - EXAFS (Fourier transform (absolute value) of $\mathrm{k}^{2}$-weighted EXAFS function, $2.7 \AA^{-1}<\mathrm{k}<14.7 \AA^{-1}$ ).

Figure $4-\mathrm{Cu} K$ XAFS spectra measured after reduction of $\mathrm{CuNa}-\mathrm{Y}(\mathrm{C})$ at different temperatures indicated in the figure, $a-$ XANES, $b$ - EXAFS (Fourier transform (absolute value) of $\mathrm{k}^{2}$-weighted EXAFS function, $2.7 \AA^{-1}<\mathrm{k}<14.7 \AA^{-1}$ ).

Figure 5 - Comparison of $\mathrm{Cu} K$ EXAFS spectra in different FAU matrices (Fourier transform (absolute value) of $\mathrm{k}^{2}$-weighted EXAFS function), a - initial (calcined) samples, 2.7 $\AA^{-1}<\mathrm{k}<14.7 \AA^{-1}, \mathrm{~b}-$ after reduction at temperatures indicated in the figure. $\mathrm{r}_{\mathrm{Cu}-\mathrm{Cu}}$ $(\AA)$, determined by fitting of the first coordination shell: $\mathrm{Cu}$ foil $-2.543 \AA, \mathrm{CuO}-$ $2.54 \AA, \mathrm{Cu}-\mathrm{DA}-\mathrm{Y}-2.53 \AA, \mathrm{CuNa}-\mathrm{Y}(\mathrm{D})-2.55 \AA, \mathrm{CuNa}-\mathrm{Y}(\mathrm{C})-2.53 \AA, \mathrm{ZnCu}-$ $\mathrm{DAY}-2.51 \AA, \mathrm{ZnCu}-\mathrm{Y}-2.53 \AA$.

Figure 6: $\mathrm{ZnK}$ XAFS spectra measured after reduction of zinc-containing Cu-FAU samples at different temperatures indicated in the figure, comparison with $\mathrm{ZnO}$ and $\mathrm{Zn}$ foil. a XANES, $\mathrm{b}$ - EXAFS (Fourier transform (absolute value) of $\mathrm{k}^{2}$-weighted EXAFS function, $\left.2.4 \AA^{-1}<\mathrm{k}<11.9 \AA^{-1}\right)$.

Figure 7: Reduction of copper oxide species in DA-Y (stationary regime, $15 \mathrm{~min}$ at temperature T) analysed from EXAFS spectra (fits of the first coordination shell), a - CuDAY, b - ZnCu-DAY. Experimental coordination numbers (C.N.) may be obtained by multiplying the normalized C.N. given in the figure with 4,2 , or 12 for $\mathrm{Cu}(\mathrm{II})$, $\mathrm{Cu}(\mathrm{I})$, and $\mathrm{Cu}(0)$, respectively. 
Figure 8: Reduction of copper oxide species in Y (static regime, $15 \mathrm{~min}$ at temperature $\mathrm{T}$ ) analysed from EXAFS spectra (fits of the first coordination shell), a - CuNa-Y(D), b $\mathrm{CuNa}-\mathrm{Y}(\mathrm{C}), \mathrm{c}-\mathrm{ZnCu}-\mathrm{Y}$. Grey shades in data points indicate $\mathrm{Cu}(\mathrm{I})$ as concluded from edge shift. Experimental coordination numbers (C.N.) may be obtained by multiplying the normalized C.N. given in the figure with 4 or 12 for $\mathrm{Cu}$ ions and $\mathrm{Cu}(0)$, respectively. Grey stars indicate cases where $\mathrm{Cu}-\mathrm{O}$ distances of $\approx 1.86 \AA$ were obtained in the fits (see text). The experimental coordination number can be obtained by multiplication with 2 in these cases (cf. Fig. 7).

Figure 9: Model analysis of the $\mathrm{Cu} K$ EXAFS spectra measured after reduction of $\mathrm{CuNa}-\mathrm{Y}(\mathrm{C})$ at $485 \mathrm{~K}$ and $595 \mathrm{~K}$ (parameters in Table 2). 


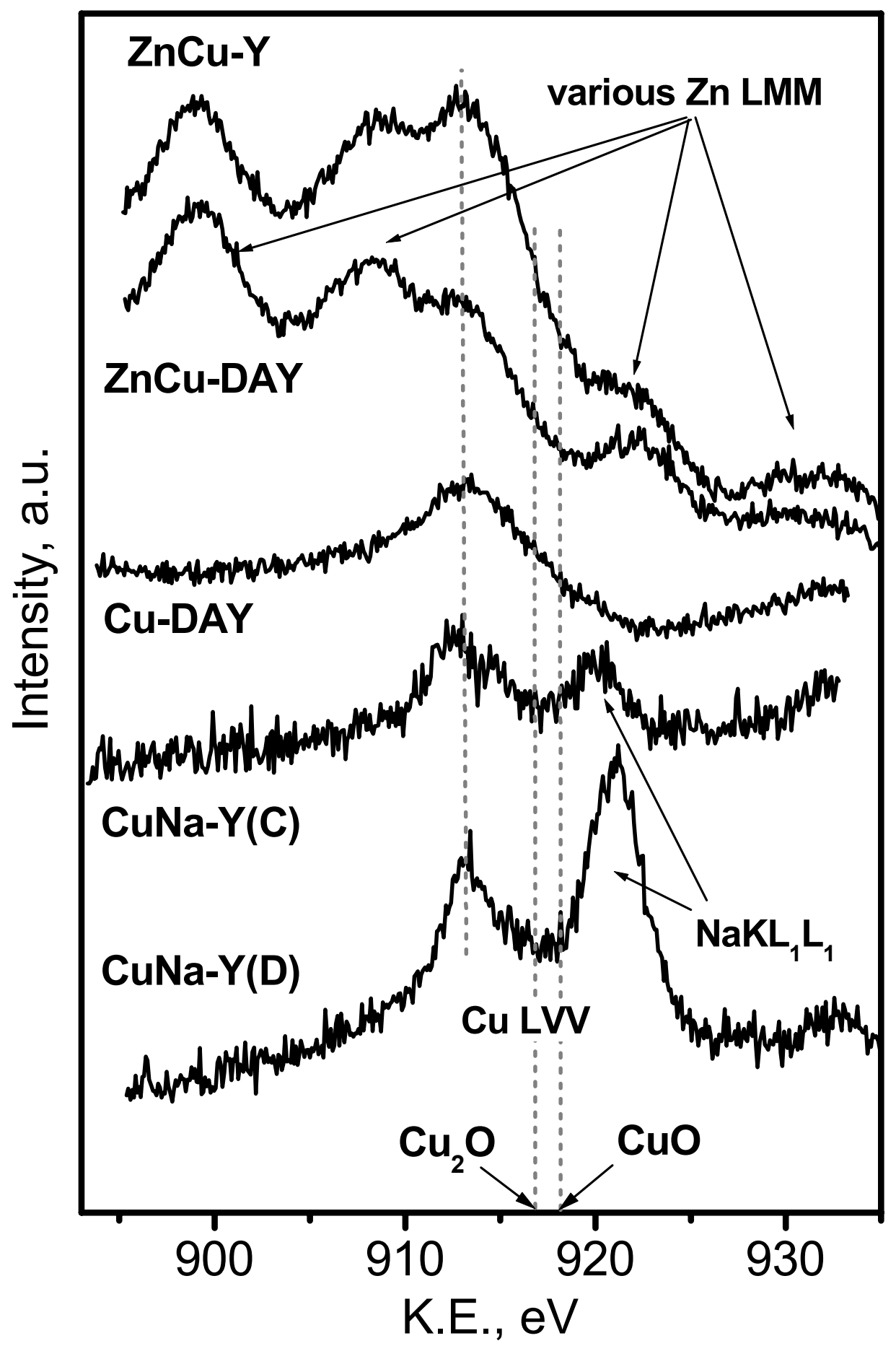

Figure 1 


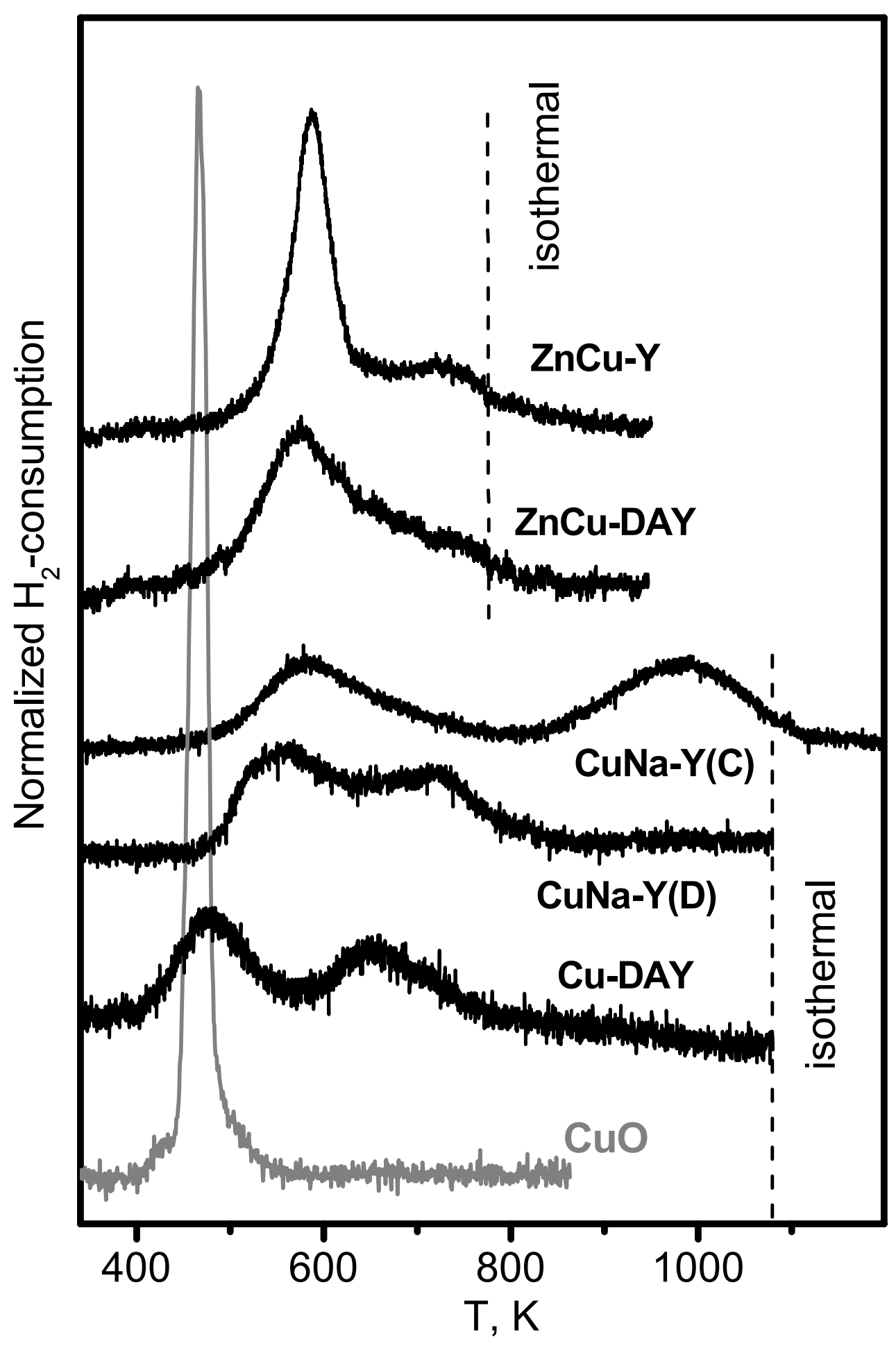

Fig. 2 

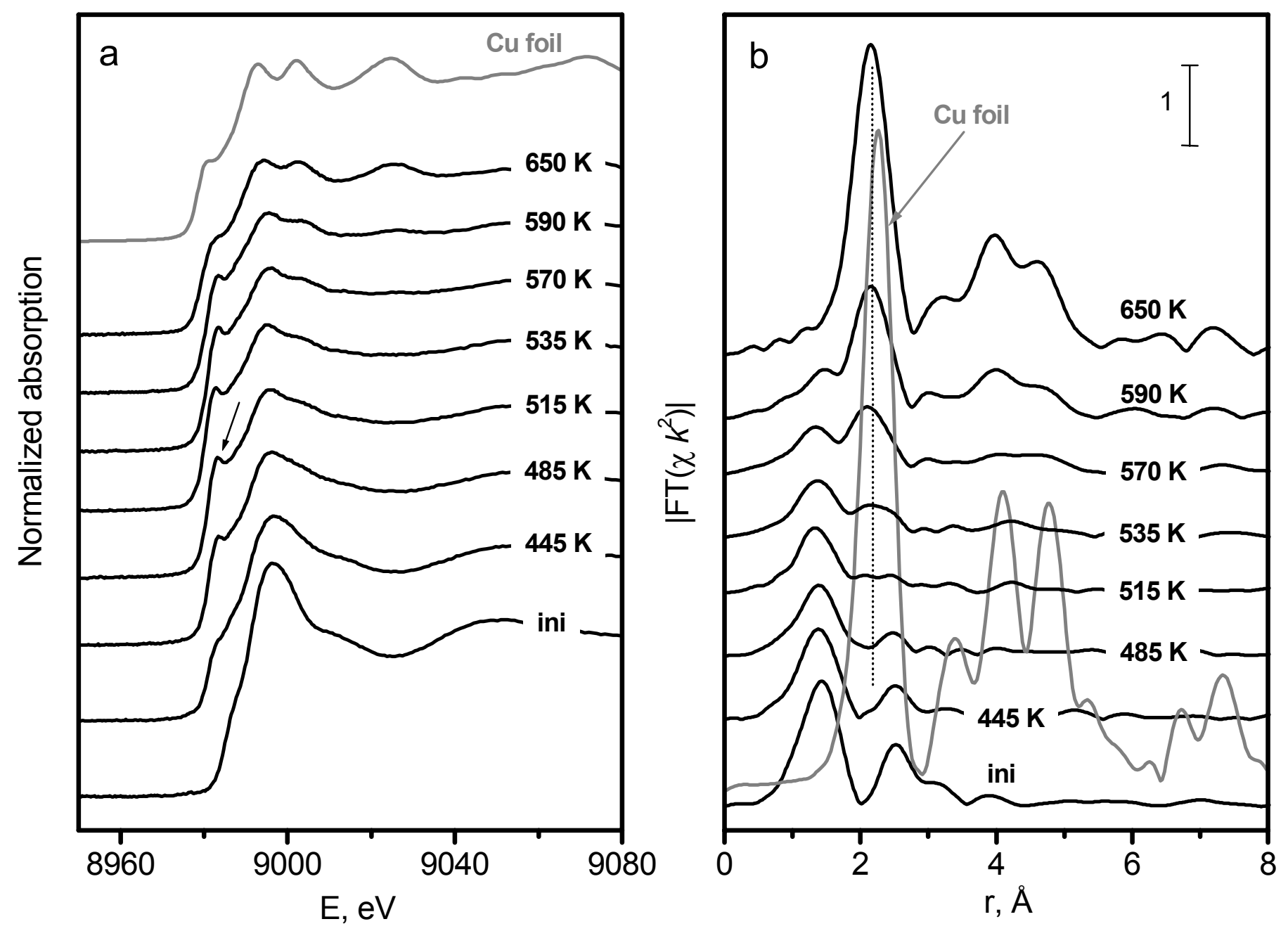

Fig. 3 

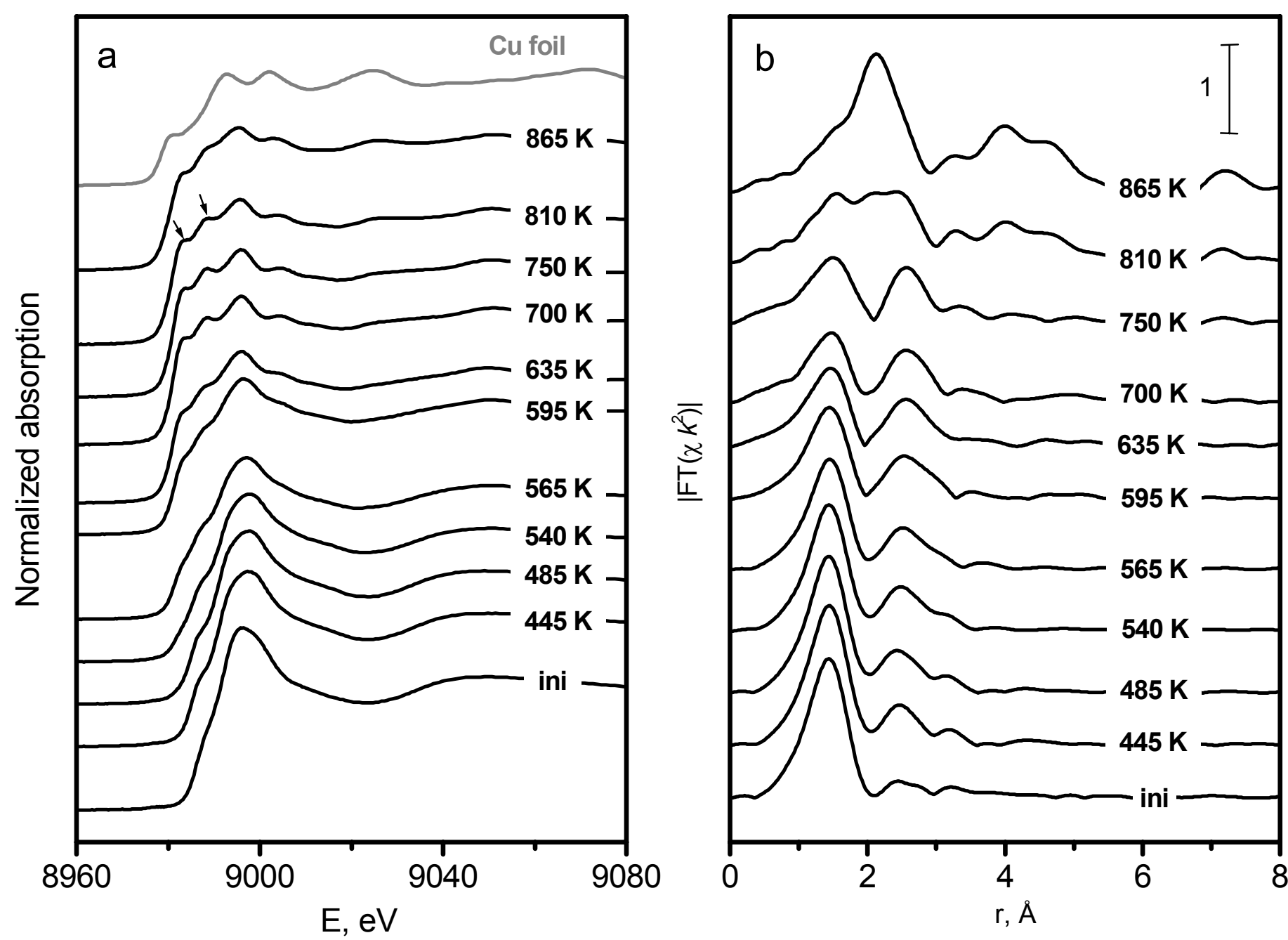

Fig. 4 

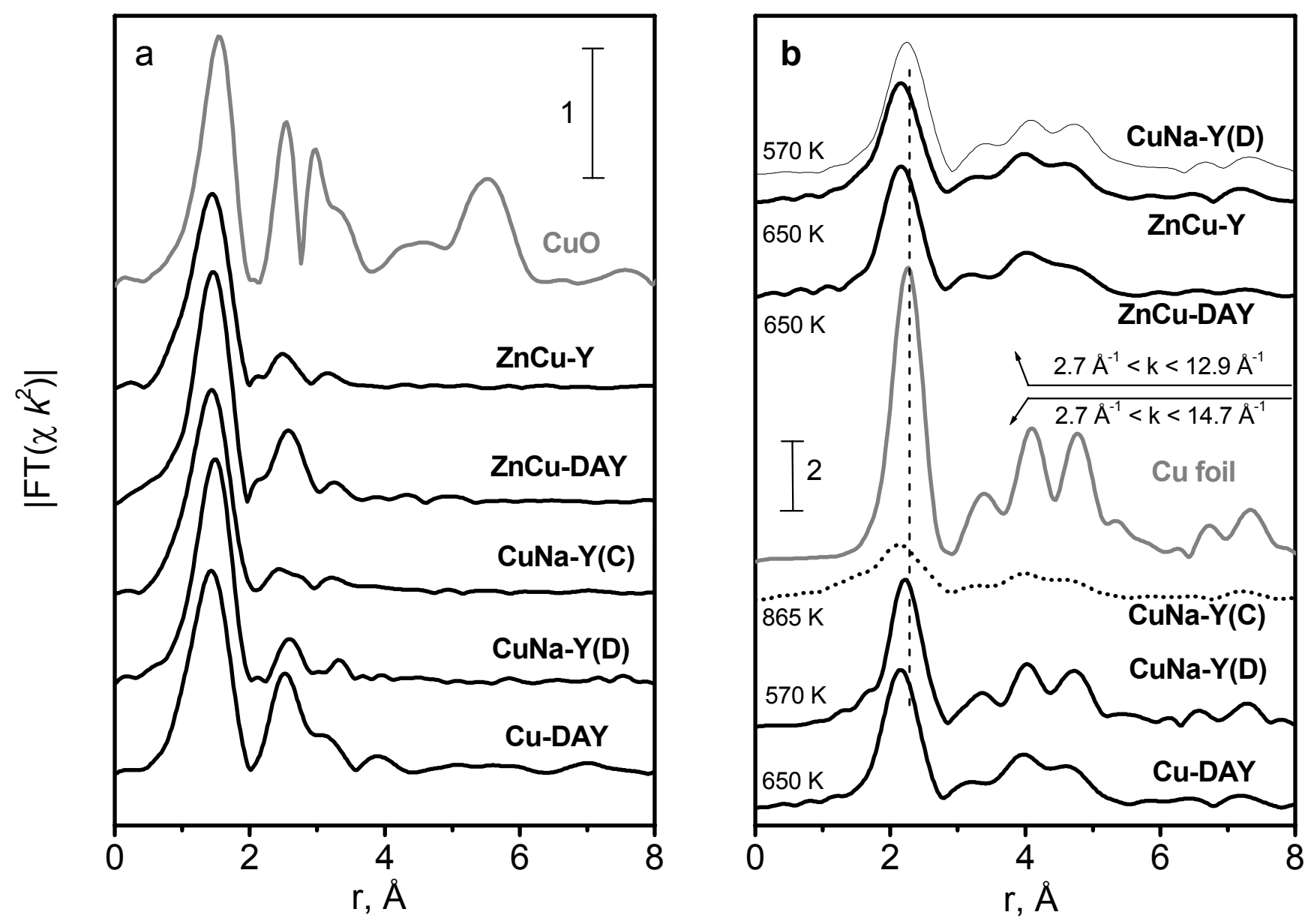

Figure 5 

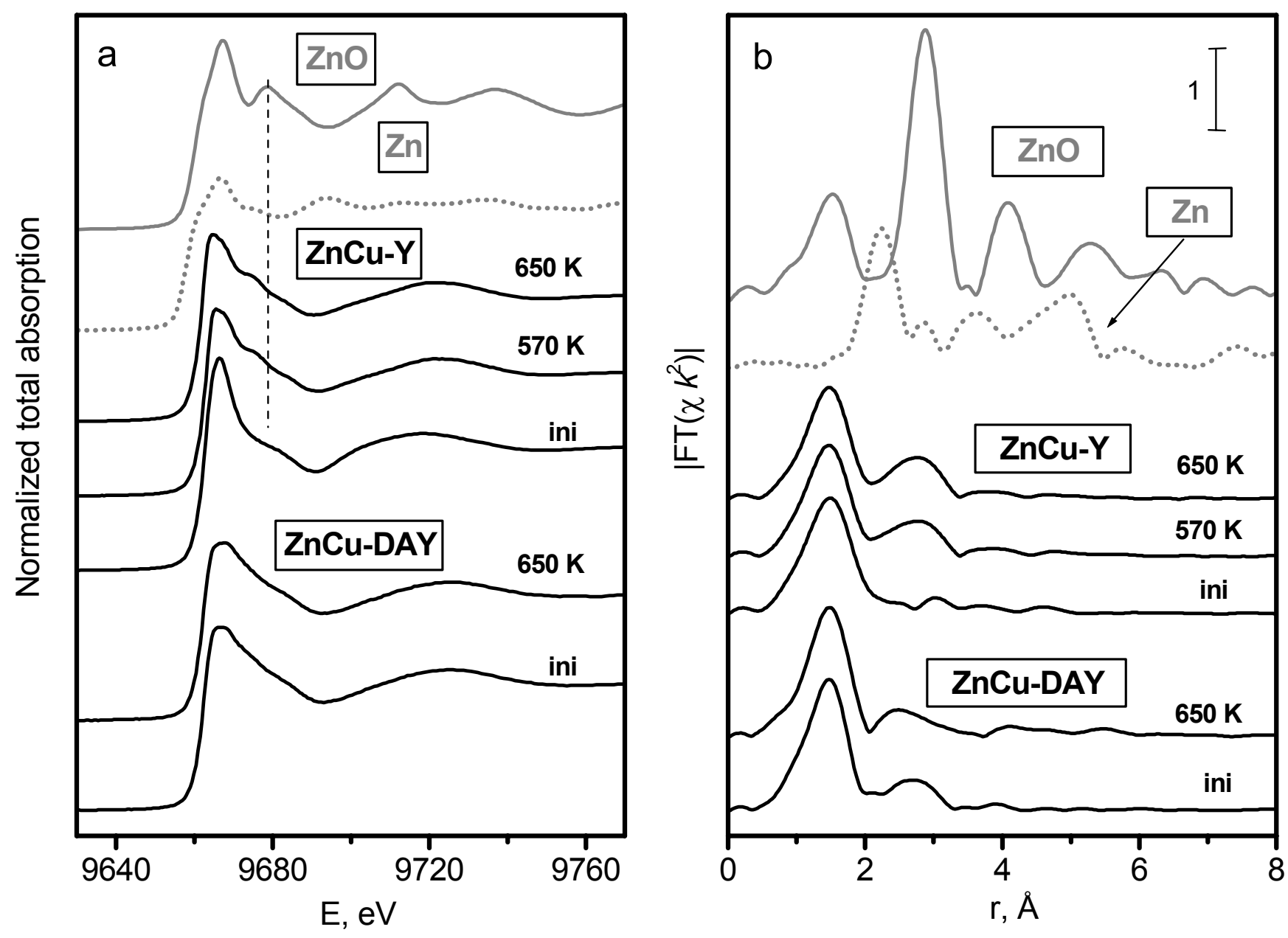

Fig. 6 

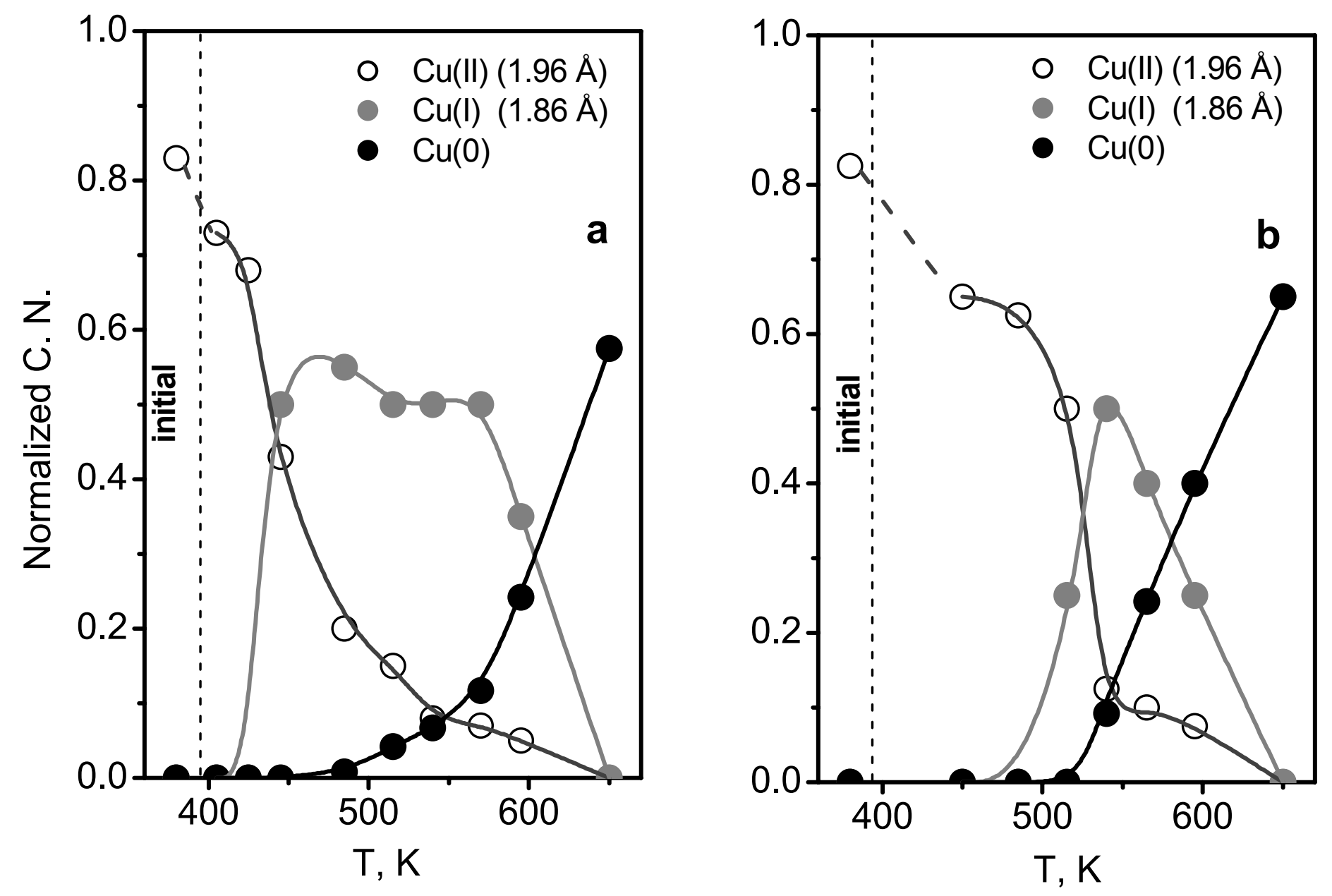

Fig. 7 

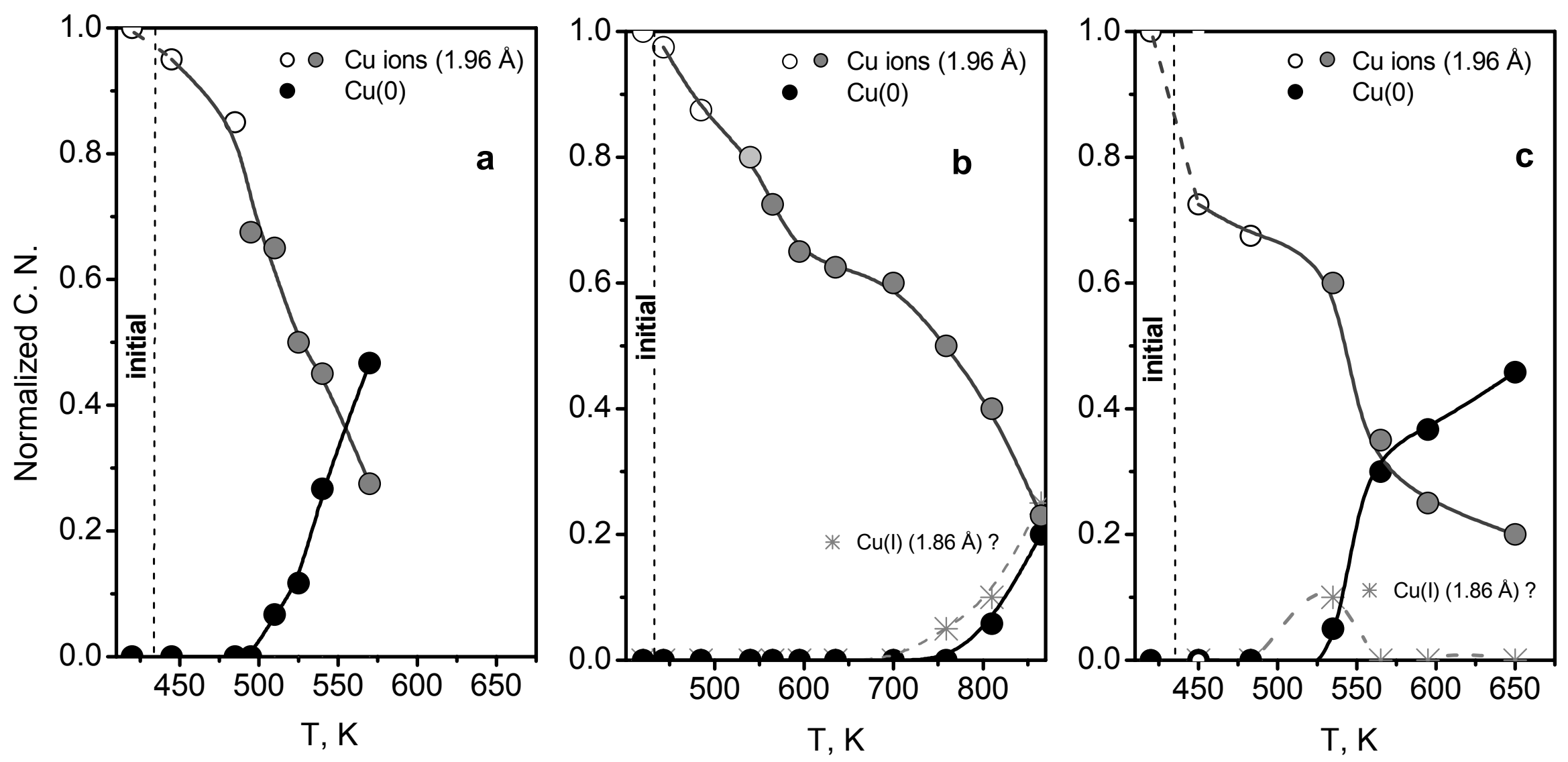

Figure 8 

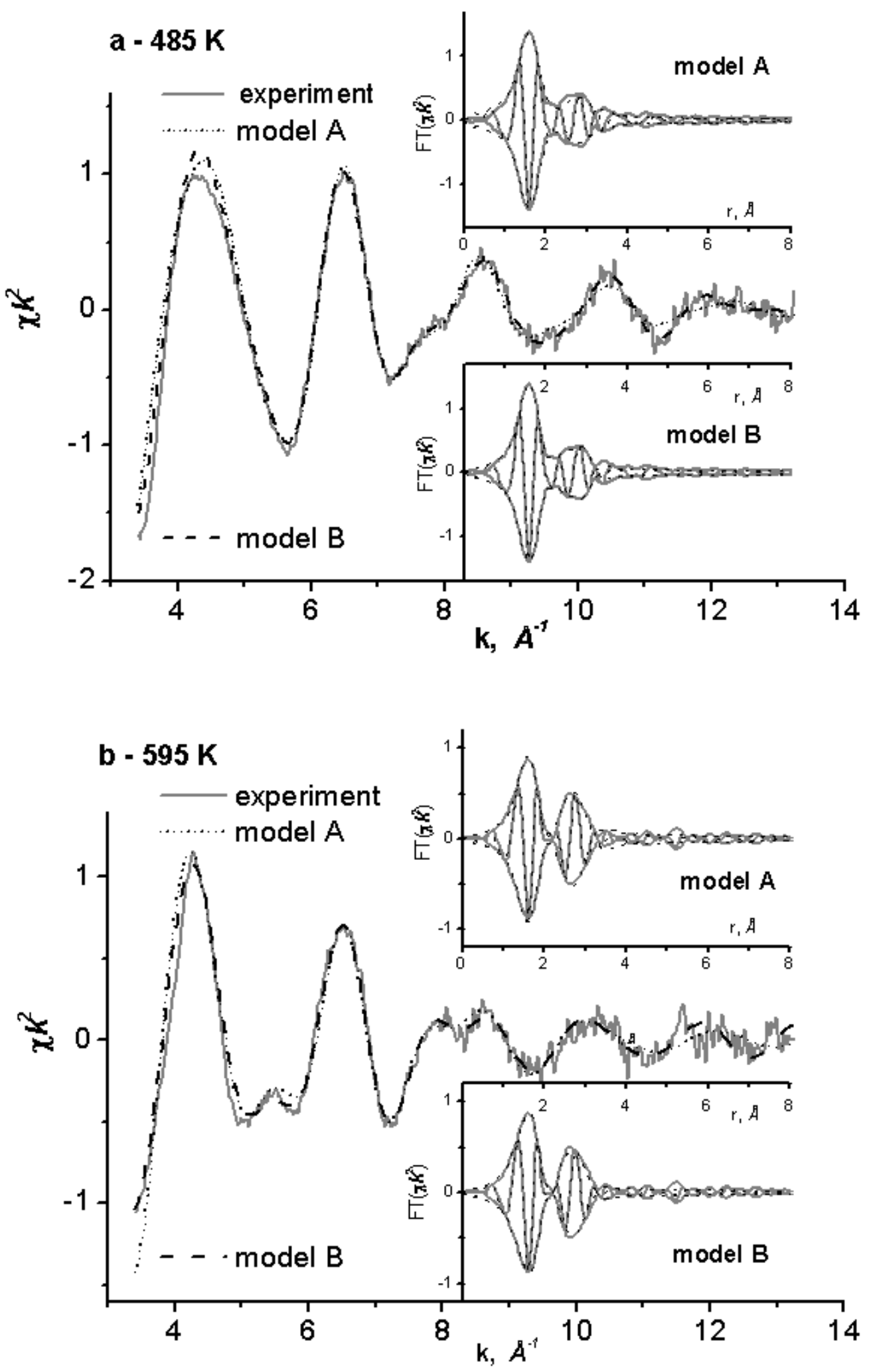

Figure 9

38 